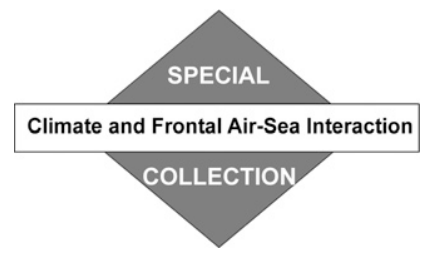

\title{
əProcesses Shaping the Frontal-Scale Time-Mean Surface Wind Convergence Patterns around the Kuroshio Extension in Winter ${ }^{\mathfrak{O}}$
}

\author{
RYUSUKE MASUNAGA \\ International Pacific Research Center, University of Hawai'i at Mānoa, Honolulu, Hawaii
}

HISASHI NAKAMURA

Research Center for Advanced Science and Technology, The University of Tokyo, Tokyo, and Japan Agency for Marine-Earth Science and Technology, Yokohama, Japan

BUNMEI TAGUCHI

Research Center for Advanced Science and Technology, The University of Tokyo, Tokyo, Japan

\section{TAKAFUMI MIYASAKA}

Japan Meteorological Business Support Center, and Meteorological Research Institute, Japan Meteorological Agency, Tsukuba, and Research Center for Advanced Science and Technology, The University of Tokyo, Tokyo, Japan

(Manuscript received 4 February 2019, in final form 17 July 2019)

\begin{abstract}
High-resolution satellite observations and numerical simulations have revealed that climatological-mean surface wind convergence and precipitation are enhanced locally around the midlatitude warm western boundary currents (WBCs) with divergence slightly to their poleward side. While steep sea surface temperature (SST) fronts along the WBCs have been believed to play an important role in shaping those frontal-scale atmospheric structures, the mechanisms and processes involved are still under debate. The present study explores specific daily scale atmospheric processes that are essential for shaping the frontalscale atmospheric structure around the Kuroshio Extension (KE) in winter, taking advantage of a new product of global atmospheric reanalysis. Cluster analysis and case studies reveal that a zonally extending narrow band of surface wind convergence frequently emerges along the KE, which is typically observed under the surface northerlies after the passage of a developed synoptic-scale cyclone. Unlike its counterpart around the cyclone center and associated cold front, the surface convergence tends to be in moderate strength and more persistent, contributing dominantly to the distinct time-mean convergence/divergence contrast across the SST front. Accompanying ascent and convective precipitation, the band of convergence is a manifestation of a weak stationary atmospheric front anchored along the SST front or generation of a weak meso- $\alpha$-scale cyclone. By reinforcing the ascent and convergence, latent heating through convective processes induced by surface convergence plays an important role in shaping the frontal-scale atmospheric structure around the KE.
\end{abstract}

D Denotes content that is immediately available upon publication as open access.

Supplemental information related to this paper is available at the Journals Online website: https://doi.org/10.1175/JCLI-D-19-0097.s1.

\footnotetext{
${ }^{a}$ Current affiliation: Faculty of Sustainable Design, University of Toyama, Toyama, Japan.
}

Corresponding author: Ryusuke Masunaga, ryusukem@hawaii.edu

\section{Introduction}

The midlatitude western boundary currents, which flow poleward along the western flank of each of the ocean basins, transport an enormous amount of heat from the tropics, releasing it into the midlatitude atmosphere in the form of turbulent sensible heat flux (SHF) and latent heat flux (LHF) while maintaining relatively warm sea surface temperature (SST) along their axes. The midlatitude oceanic frontal zones, which are characterized by steep gradients in SST along the 
poleward flanks of the major midlatitude western boundary currents and their extensions (for brevity, herein referred to as WBCs), play an important role in shaping the mean state of the midlatitude atmospheric circulation (Kwon et al. 2010; Nakamura et al. 2004), including the anchoring of storm tracks and maintenance of their activity (e.g., Hoskins and Valdes 1990; Nakamura et al. 2004, 2008). Investigation of their detailed roles was, however, hindered by narrow meridional widths of the WBCs (typically, 100-200 km) and intensive weather noise in the midlatitudes (e.g., Xie 2004).

Recent implementation of high-resolution satellite measurements and numerical modeling has substantially advanced our understanding of the influence of SST and its variability around the WBCs on frontal-scale atmospheric features in addition to the basin-scale atmospheric features. Today, it has been well established that distinct surface wind convergence forms along the axes of the WBCs and strong divergence slightly poleward where SST gradients are maximized (e.g., O'Neill et al. 2003, 2005, 2010, 2012; Chelton and Xie 2010; Minobe et al. 2008; Masunaga et al. 2015). The enhanced convergence accompanies enhanced precipitation and ascent, which can reach the tropopause level in summer (Tokinaga et al. 2009; Minobe et al. 2010). These frontal-scale atmospheric features have been modulated in association with the interannual-to-decadal variability of the WBCs (Wang and Liu 2015; Masunaga et al. 2016).

The narrow bands of surface wind convergence and divergence have been interpreted as a manifestation of local responses of the marine atmospheric boundary layer (MABL) to steep SST gradients, as reviewed by Small et al. (2008). Vigorous surface turbulent heat fluxes around the warm WBCs heat the overlying MABL locally, affecting sea level pressure (SLP) and thereby yield frictional surface wind convergence/ divergence (i.e., "hydrostatic effect"; Lindzen and Nigam 1987). Indeed, a local SLP trough along the Kuroshio Extension (KE) is identified in the wintertime climatology (Tanimoto et al. 2011). Takatama et al. (2012, 2015) argued through simple diagnostics that the hydrostatic effect plays a primary role in shaping the climatological-mean surface wind convergence extending along the KE and Gulf Stream. Meanwhile, modifications in static stability within the MABL through surface heat fluxes lead to modulations in downward transport of large wind momentum via turbulent mixing and thereby in surface convergence/divergence around the SST fronts (Wallace et al. 1989; Hayes et al. 1989). Through this "vertical mixing effect," time-mean surface wind divergence is expected right over the SST fronts under the background winds blowing from their colder to warmer sides.

There has been a long debate as to the relative importance between those two processes in forming the time-mean surface convergence/divergence. An idealized MABL model (Schneider and Qiu 2015) and numerical experiments with simple two-dimensional configurations (Song et al. 2006; Spall 2007; Kilpatrick et al. 2014, 2016) suggest that the relative importance between those two processes tends to be sensitive to background wind speed in the cross-SST front direction. Specifically, the vertical mixing effect is more effective when background winds are strongly across SST fronts, whereas the hydrostatic effect is more effective when background wind blows along SST fronts.

Recent studies, however, suggest important contributions from synoptic-scale atmospheric disturbances that accompany strong surface wind convergence/ divergence to the time-mean structures (e.g., Parfitt and Seo 2018). Steep SST fronts associated with the WBCs act to sustain recurrent development of synoptic-scale disturbances by maintaining near-surface atmospheric baroclinicity efficiently through SHF (e.g., Nakamura et al. 2004, 2008; Sampe et al. 2010; Hotta and Nakamura 2011; Ogawa et al. 2012). It has been pointed out that SST anomalies near the WBCs can modify individual synoptic-scale disturbances. Ascent on the warm sector of individual cyclones tends to strengthen above the Gulf Stream axis, where the warm SST locally destabilizes the lower troposphere (Sheldon et al. 2017). Detection frequency of atmospheric fronts tends to increase in the vicinity of the Gulf Stream, since the SHF contrast across the associated SST front can act to strengthen atmospheric fronts (Parfitt et al. 2016, 2017b). Furthermore, O'Neill et al. (2017) argued that these infrequent atmospheric disturbances that accompany extreme wind convergence leave significant imprints on the time-mean fields, and therefore examining the time-mean structure alone may be insufficient to provide conclusive evidence that local MABL processes discussed above are indeed operative.

It is thus still an open question as to the relative contributions from these potentially operative processes in shaping the SST-frontal-scale atmospheric patterns in their time-mean distribution. In the present study, we explore the specific formation processes and mechanisms for the surface wind convergence/ divergence and associated ascent and precipitation over the $\mathrm{KE}$ region, by examining daily scale atmospheric evolution.

The rest of the present study is organized as follows. The datasets used in the present study are introduced in 
section 2. In sections 3 and 4, we explore the typical strength of surface convergence/divergence that plays a major role in shaping the time-mean pattern. In sections 5 and 6, we describe typical daily scale atmospheric events that contribute to the time-mean atmospheric structure, where we point out the importance of stationary atmospheric fronts anchored along the KE. In section 7 we discuss their specific mechanism, where we emphasize an important role of convective processes. A summary and discussion are given in section 8 .

\section{Data}

\section{a. JRA-55CHS}

In the present study, we mainly use a new additional product of the Japanese 55-yr Reanalysis (JRA-55) project of the Japan Meteorological Agency (JMA) called JRA-55CHS (Masunaga et al. 2018). The atmospheric forecast model of JRA-55CHS is the same as the one used for the main product of JRA-55 (Kobayashi et al. 2015; Harada et al. 2016) and JRA-55 Conventional (Kobayashi et al. 2014). The horizontal resolution is TL319 (equivalent to $\sim 55-\mathrm{km}$ resolution) with 60 sigma-pressure hybrid vertical levels.

For the lower-boundary condition, JRA-55CHS uses the Merged Satellite and In Situ Global Daily Sea Surface Temperature (MGDSST) data produced by JMA, which is available with $0.25^{\circ}$ resolution over the globe from January 1982. Unlike the Centennial ObservationBased Estimates of SST (COBE-SST; Ishii et al. 2005) data with $1^{\circ}$ resolution used for the main product of JRA-55, the MGDSST data can resolve steep SST gradients along the major WBCs. JRA-55CHS can thus represent thermal impacts of the WBCs on the overlying atmosphere (Masunaga et al. 2018). It should be noted that no satellite observations for the atmosphere are assimilated for JRA-55CHS to ensure homogeneity of data quality over the whole data period. Although JRA55CHS is available for the period from January 1982 to December 2012, MGDSST product may not be reliable for the first three years due to insufficient satelliteborne observations for SST. Our analysis period therefore starts in January 1985 and the 28-yr climatologies are defined.

For our analysis we use 6-hourly outputs of zonal and meridional 10-m surface wind components, SLP, SHF, and LHF in the JRA-55CHS data. Although 10-m surface wind can be sensitive to MABL parameterization schemes, we have confirmed that horizontal wind at the lowest model level provides similar results. We also use total and convective precipitation, which are averaged over $6 \mathrm{~h}$ centered at a given time scaled as millimeters per day $\left(\mathrm{mm} \mathrm{day}^{-1}\right)$. As described in Masunaga et al. (2018), precipitation of the JRA-55 family seems rather oversensitive to underlying SST anomalies. Nevertheless, the frontal-scale distribution in climatology is consistent with satellite observations. We also use a three-dimensional distribution of air temperature, specific humidity, pressure vertical velocity, and diabatic heating rate from convective processes, which are available 6-hourly on a pressure coordinate.

\section{b. ERA5}

Recognizing that reanalysis products, especially precipitation, can be sensitive to forecast models and data assimilation systems, we utilize ERA5 (Hersbach et al. 2018; Copernicus Climate Change Service 2017) for validation. The horizontal resolution is TL639 (equivalent to $\sim 31-\mathrm{km}$ resolution) with 137 sigma-pressure hybrid vertical levels. ERA5 is currently available from January 1979 on a $0.25^{\circ} \times 0.25^{\circ}$ grid system. The resolution of prescribed SST is $0.25^{\circ} \times 0.25^{\circ}$ until August 2007 and $0.05^{\circ} \times 0.05^{\circ}$ afterward (Hersbach et al. 2018). We have briefly verified that the horizontal structures in monthly mean SST and surface wind convergence fields are overall consistent between ERA5 and JRA-55CHS during our analysis period, while ERA5 tends to exhibit stronger SST gradients and wind convergence probably due to its higher horizontal resolution.

\section{c. Satellite observations}

For validation of sea surface wind structures in the reanalysis products, we utilize the National Aeronautics and Space Administration's (NASA) Quick Scatterometer (QuikSCAT) measurements produced by Remote Sensing Systems (Ricciardulli and Wentz 2011) for the period September $1999-$ October 2009 on a $0.25^{\circ} \times$ $0.25^{\circ}$ grid system. We applied 9-point average smoothing, with weight of unity for a given grid point, 0.5 for the four nearest points, and 0.25 for the other four points, to the zonal and meridional wind components before computing convergence.

\section{Climatological-mean distributions and "extreme-value filter"}

Climatological-mean surface wind convergence and surface heat fluxes over the Kuroshio-Oyashio Extension (KOE) region east of Japan are the strongest in cold seasons based on in situ and satellite observation (Tokinaga et al. 2009; Tanimoto et al. 2011). To investigate typical wintertime features, we focus on the midwinter month (January) in the following analysis. Nevertheless, we have confirmed that statistical features in sections 3 and 4 are consistent among the three winter 

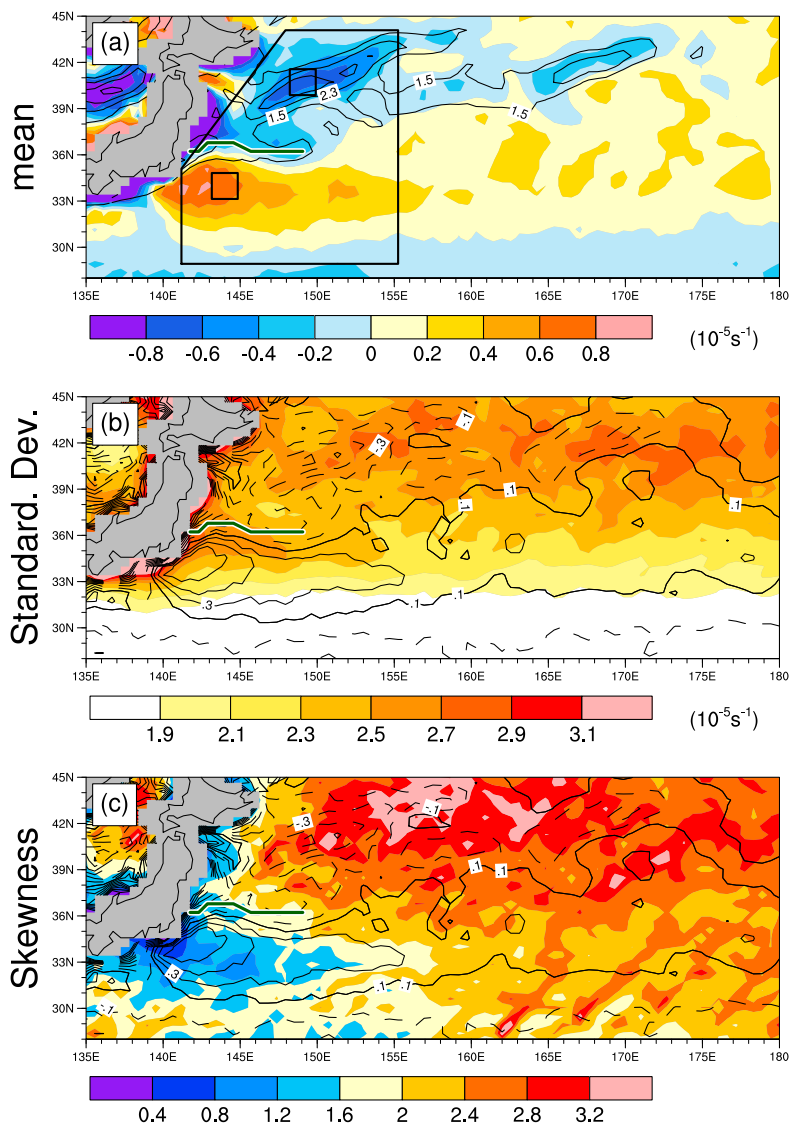

FIG. 1. (a) January climatologies of surface wind convergence (shaded; $10^{-5} \mathrm{~s}^{-1}$ ) and SST gradient [contoured for every $0.8^{\circ} \mathrm{C}$ $(100 \mathrm{~km})^{-1}$ from $1.5^{\circ} \mathrm{C}(100 \mathrm{~km})^{-1}$ ] over the Kuroshio-Oyashio Extension region for the period 1985-2012 based on the JRA55CHS. (b) As in (a), but the corresponding standard deviation estimated on a 6-hourly basis (shaded; $10^{-5} \mathrm{~s}^{-1}$ ) and climatologicalmean distribution of surface wind convergence (contoured for every $0.2 \times 10^{-5} \mathrm{~s}^{-1}$ from $\pm 0.1 \times 10^{-5} \mathrm{~s}^{-1}$ ). (c) As in (b), but for skewness (shaded) instead of standard deviation. Small and large boxes in (a) indicate domains for which histograms and reference percentiles in Fig. 4 are estimated. Green lines indicate the axis of the KE Front at which climatological-mean horizontal SST gradients are locally maximized.

months (December, January, February). Also, ERA5 exhibits qualitatively consistent results.

Figure 1a shows January climatologies of surface wind convergence and SST gradients around the KE. In the climatologies, local maxima of surface wind convergence are organized along the $\mathrm{KE}$ and divergence slightly to its poleward side, which is consistent with satellite observations (Fig. A1). Furthermore, JRA$55 \mathrm{CHS}$ well represents narrow bands of enhanced precipitation along the KE and associated ascent (Fig. 2), as described in previous studies (e.g., Minobe et al. 2010; Tokinaga et al. 2009; Masunaga et al. 2015). The northward tilt of ascent in the KOE region, as observed
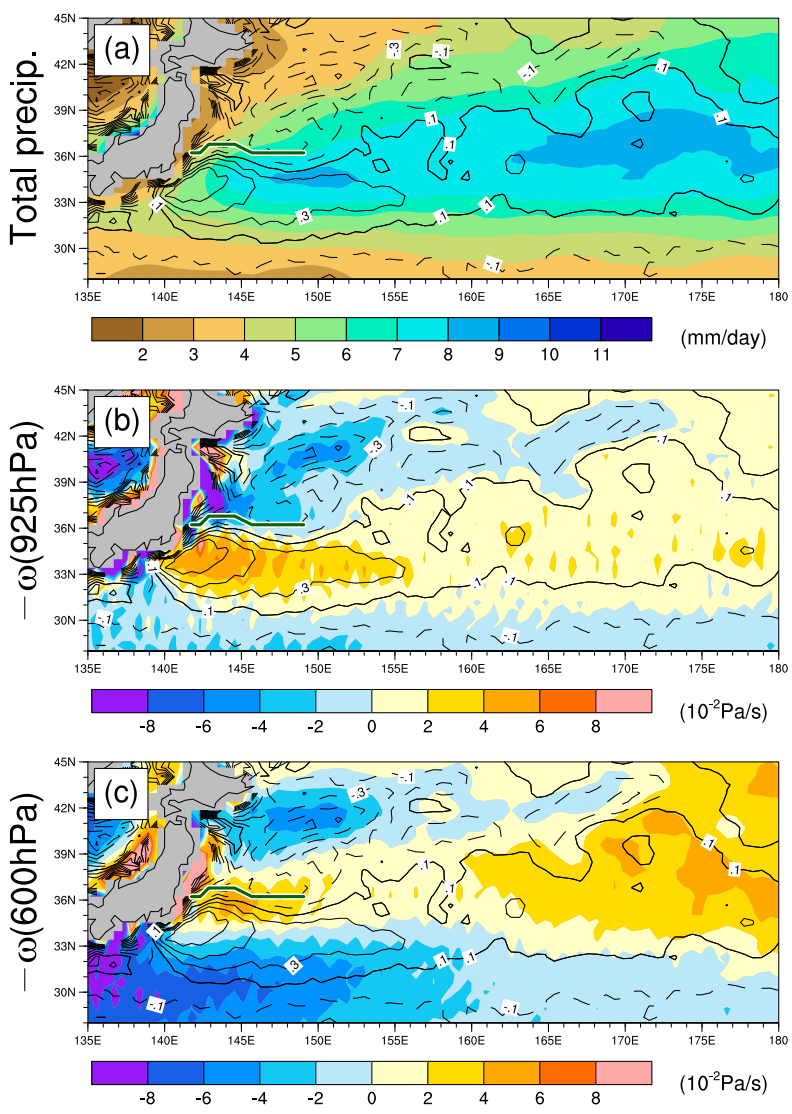

FIG. 2. As in Fig. 1, but for January climatologies of (a) total precipitation ( $\mathrm{mm} \mathrm{day}^{-1}$; shaded), (b) vertical velocity as sign-reversed pressure velocity at $925 \mathrm{hPa}$, and (c) $600 \mathrm{hPa}\left(10^{-2} \mathrm{~Pa} \mathrm{~s}^{-1}\right.$; shaded) for the period 1985-2012 based on JRA-55CHS for the $\mathrm{KOE}$ region. Contours in (a)-(c) indicate the corresponding January climatology of surface wind convergence (every $0.2 \times$ $10^{-5} \mathrm{~s}^{-1}$ from $\pm 0.1 \times 10^{-5} \mathrm{~s}^{-1}$ ).

between the 925 and $600 \mathrm{hPa}$ levels (Figs. 2b,c), is consistent with other atmospheric reanalysis products, including the ERA5 (not shown) and JRA-25 (Minobe et al. 2010).

To examine the role of extreme events in the JRA$55 \mathrm{CHS}$, we apply the "extreme-value filter" (O'Neill et al. 2017), in which filtered climatology is evaluated with discarding extreme events where local anomalies exceed \pm 2 standard deviations, to daily fields of January surface wind convergence in JRA-55CHS over the KOE region. In the filtered climatologies (Fig. 3b), the wind convergence over the KE is substantially weakened. The contribution from those extreme events is, however, horizontally uniform (Fig. 3c), acting to yield spatially homogenous time-mean surface wind convergence. Removing those extremes thus eventually leads to strengthening in surface wind divergence (i.e., stronger negative values) poleward of the KE axis (Fig. 3b). Thus, the spatial 

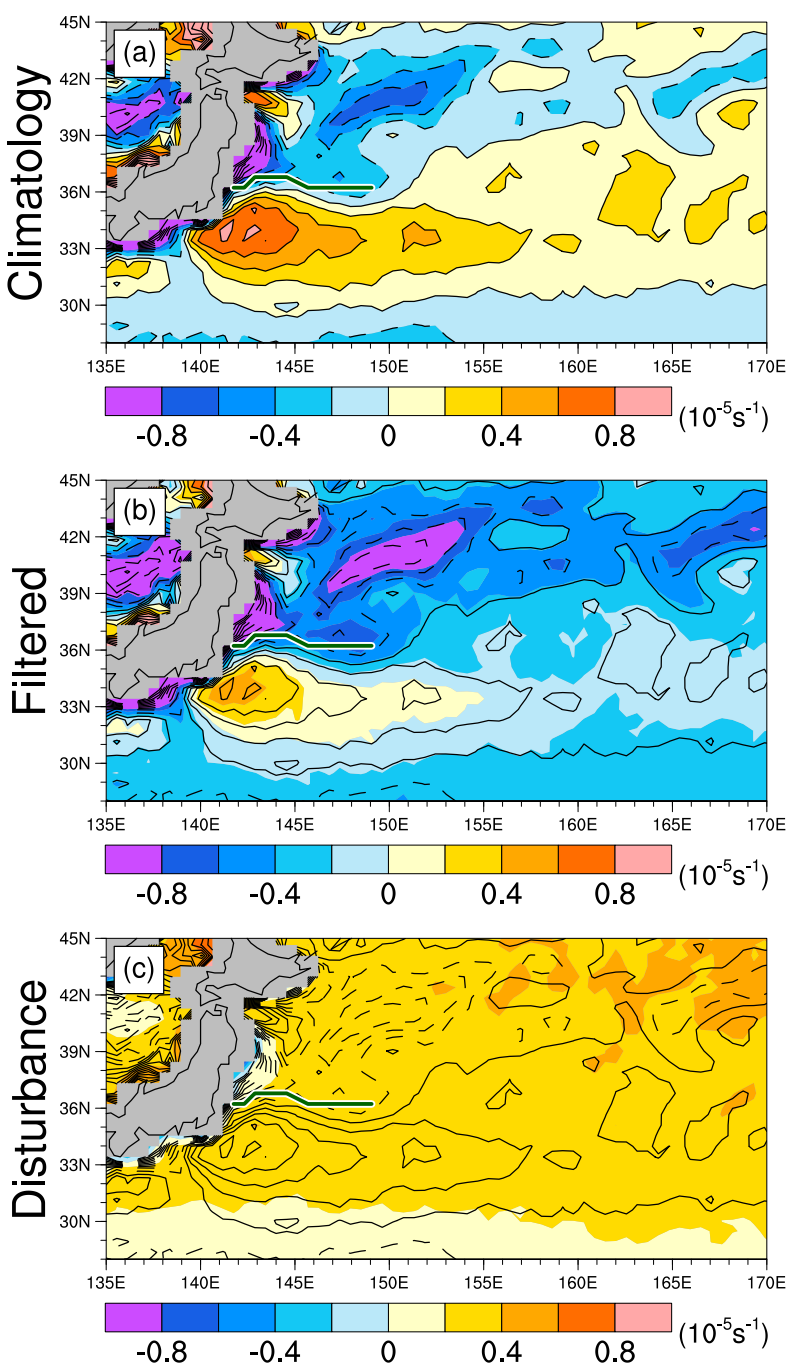

FIG. 3. As in Fig. 1 but for (a) January climatology of surface wind convergence over the Kuroshio-Oyashio Extension region based on JRA-55CHS for the period 1985-2012 (shaded) and (b) the corresponding extreme-value-filtered field defined by O'Neill et al. (2017). (c) Contribution from extreme events evaluated as difference between climatological-mean and extremevalue filtered distribution [i.e., (a) minus (b)]

inhomogeneity characterized by convergence maxima over the KE axis and divergence maxima poleward is retained even after applying the extreme-value filter as in the simple climatology (Fig. 3a). These features are consistent with annual statistics based on the satellite observations for the Gulf Stream region given by O'Neill et al. (2017). As shown in Figs. 1b and 1c, both standard deviation and positive skewness of surface wind convergence estimated on a daily basis tend to be smaller along the climatologicalmean surface wind convergence maxima along the KE than on their poleward sides. This tendency implies a relatively small contribution from extreme convergence events to the frontal-scale time-mean surface wind convergence maxima along the $\mathrm{KE}$.

Although the corresponding distribution is rather noisy, QuikSCAT yields essentially consistent results (appendix A). Compared to the JRA-55CHS climatology, however, extreme events yield greater contributions to the enhanced QuikSCAT convergence over the KE. Nevertheless, it is unlikely that the time-mean surface wind convergence pattern on a frontal scale is shaped only by direct contributions from extreme convergence/divergence events associated with synopticscale disturbances, as pointed out by O'Neill et al. (2017) and Plougonven et al. (2018). Since the timemean distributions can thus be significantly affected by atmospheric disturbances, examining the former alone seems insufficient to fully understand local impacts of SST fronts on the MABL. In the following sections, we examine daily scale wind convergence events to investigate the processes operative in shaping the frontalscale climatological-mean patterns.

\section{Frequency and contributions}

\section{a. Histograms}

Figure 4a shows histograms of surface wind convergence within two small rectangular boxes indicated in Fig. 1a; one is near the climatological-mean maximum of surface wind convergence over the KE, and the other near the surface wind divergence maximum near the Oyashio Front (red and blue lines, respectively). Gray vertical lines indicate reference percentile values estimated for the entire KOE region (larger box in Fig. 1a) on a 6-hourly basis. In the present study, we classify the magnitudes of wind convergence and divergence into eight categories based on those reference percentile values (Table 1).

These histograms are both characterized by negative mode and positive skewness $(+1.3$ for the convergence maximum, +2.8 for the divergence maximum), which are consistent with satellite observations around the Gulf Stream (O'Neill et al. 2017). The histogram near the Oyashio exhibits greater positive skewness as a manifestation of more frequent weak-to-moderate divergence events and occasional occurrence of extreme convergence events associated probably with synopticscale cyclones and associated fronts. The difference in convergence frequency between the two locations (i.e., red minus blue) is distinct for weak-to-moderate events, while the difference decreases with convergence strength and becomes negligible for extreme convergence events. Likewise, the difference in divergence frequency is the largest for weak-to-moderate events, but negligible for extreme divergent events. 
(a) Frequency (\%), KOE

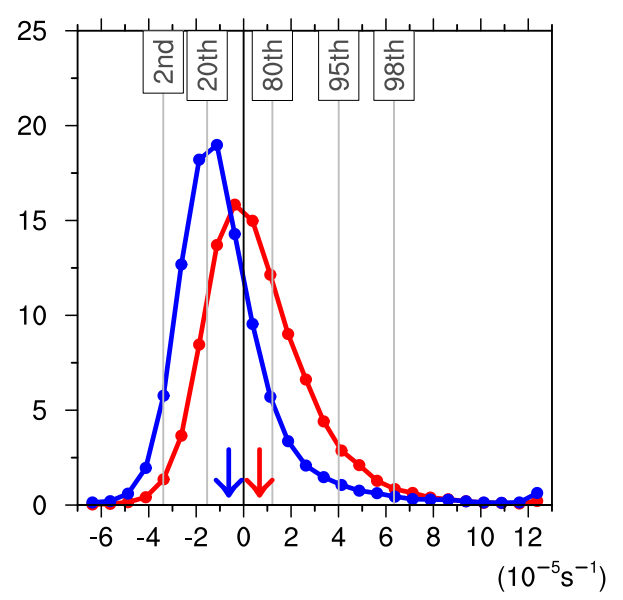

(b) Contribution $\left(10^{-5} \mathrm{~s}^{-1}\right), \mathrm{KOE}$

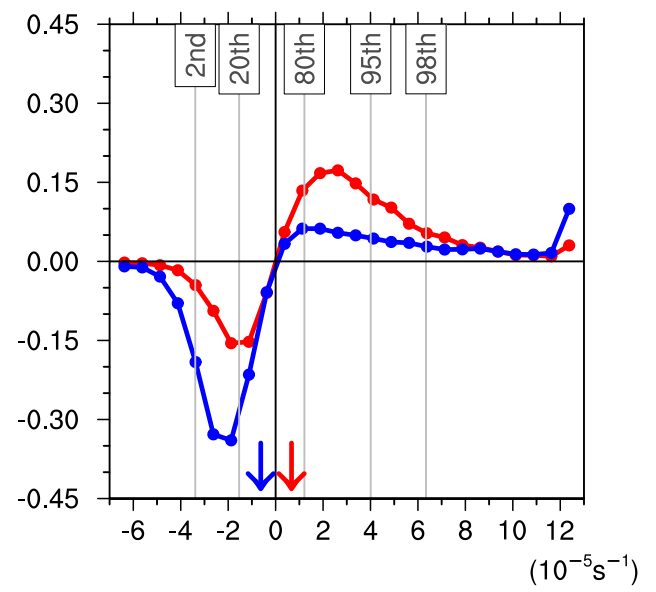

(c) Accumulation $\left(10^{-5} \mathrm{~s}^{-1}\right), \mathrm{KOE}$

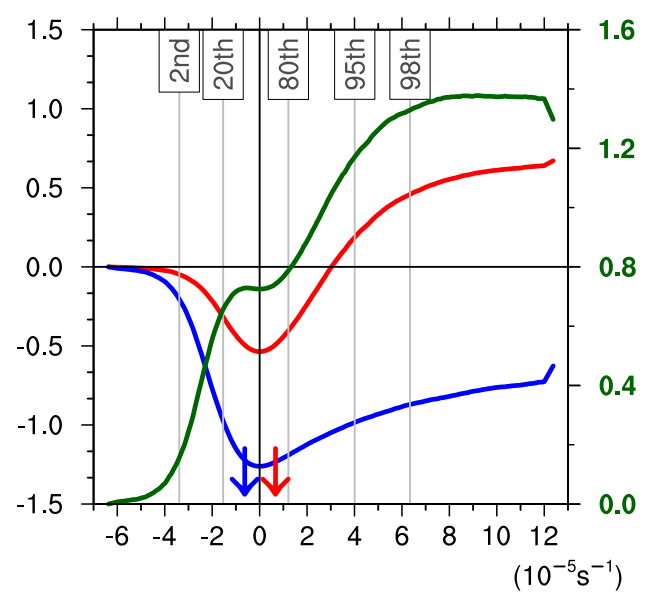

FIG. 4. (a) Histogram of 6-hourly surface wind convergence in January for the period 1985-2012 near the Kuroshio Extension $\left(143.438^{\circ}-144.563^{\circ} \mathrm{E}, 33.416^{\circ}-34.54^{\circ} \mathrm{N}\right.$; red; left axis) and Oyashio Front $\left(148.5^{\circ}-149.625^{\circ} \mathrm{E}, 40.156^{\circ}-41.279^{\circ} \mathrm{N}\right.$; blue; left axis),
For a more quantitative assessment, the corresponding contribution from a given bin to the local climatological mean is evaluated as the product of the frequency and mean value of the bin (Parfitt and Czaja 2016; Vannière et al. 2017). This may be expressed as

$$
\frac{N_{\text {bin }(i)}}{N_{\text {all }}} \times \frac{1}{N_{\text {bin }(i)}} \sum_{\operatorname{bin}(i)} \operatorname{CONV}_{\operatorname{bin}(i)}=\frac{1}{N_{\text {all }}} \sum_{\operatorname{bin}(i)} \operatorname{CONV}_{\text {bin }(i)},
$$

where $N_{\text {bin }(i)}$ and $N_{\text {all }}$ denote the number of samples in the $i$ th bin and the total number of samples, respectively. The latter is equal to the total 6-hourly samples within each of the small boxes indicated in Fig. 1a. In (1), $\operatorname{CONV}_{\text {bin }(i)}$ signifies the set of individual convergence samples falling within each bin. By definition, the sum of the contributions from all the bins equals the climatological-mean value for the small box. The contribution near the KE (red line in Fig. 4b) and its difference (not shown) from its counterpart near the Oyashio exhibit a distinct positive peak at moderate convergence strength, indicative of their primary significance in shaping the meridional contrast in climatology. By contrast, the difference in contribution becomes smaller for the strong to extreme convergence events or even changes its sign at the rightmost bin. Likewise, the corresponding difference in contributions from surface wind divergence exhibits a distinct negative peak at a moderate strength, and the difference rapidly becomes smaller toward stronger divergence.

The importance of moderate events can be further clarified by accumulating the contributions from negative infinity to a particular value (Fig. 4c). A contribution from each category can be evaluated as the difference between the accumulated values at the larger and smaller thresholds of the category and summarized in Table 2. For example, contribution from the moderate events on the warmer side of the KE (the second row and third column of Table 2) is evaluated as 0.19 minus -0.40 , which are the

\footnotetext{
$\longleftarrow$

corresponding to the southern and northern small boxes, respectively, in Fig. 1a. Red and blue arrows indicate the corresponding climatological-mean values of these distributions. Gray vertical lines indicate reference percentile values of surface wind convergence within the entire KOE region (larger gray box in Fig. 1a). (b) As in (a), but for their corresponding contributions to the climatologicalmean values estimated as the products of frequency and average values of individual bins. (c) As in (b), but integrated from negative infinity to a particular value along the abscissa, and their difference (red minus blue; green line; right green ordinate). Note that all of the samples larger (smaller) than $12 \times 10^{-5} \mathrm{~s}^{-1}\left(-6 \times 10^{-5} \mathrm{~s}^{-1}\right)$ are included in the rightmost (leftmost) bin.
} 
TABLE 1. Classification and the corresponding magnitudes of surface wind convergence/divergence events.

\begin{tabular}{lcc}
\hline \hline \multicolumn{1}{c}{ Category } & $\begin{array}{c}\text { Magnitude } \\
\left(\times 10^{-5} \mathrm{~s}^{-1}\right)\end{array}$ & $\begin{array}{c}\text { Reference } \\
\text { percentile }\end{array}$ \\
\hline Extreme convergence & $>6.34$ & $>98$ th \\
Strong convergence & $4.01-6.34$ & 95 th -98 th \\
Moderate convergence & $1.21-4.01$ & 80 th -95 th \\
Weak convergence & $0-1.21$ & 59.3 th -80 th \\
Weak divergence & -1.54 to 0 & 20th-59.3th \\
Moderate divergence & -2.71 to -1.54 & 5th-20th \\
Strong divergence & -3.39 to -2.71 & 2nd-5th \\
Extreme divergence & $<-3.39$ & $<2$ nd \\
\hline
\end{tabular}

accumulated values illustrated with the red line at the reference 95th and 80th percentiles along the abscissa. Note that the right most end of each line exactly equals the corresponding climatological-mean value. Although the frequency of strong to extreme events accounts only for $\sim 6 \%$ of the total samples, those events contribute significantly to the local time-mean values (first and second rows in Table 2), as discussed by O'Neill et al. (2017). However, moderate events make 3 times as large a contribution as strong to extreme events to the difference (third row in Table 2, green line in Fig. 4c), which highlights the frontal-scale meridional contrast. Meanwhile, the corresponding contribution from weak events is negligible. As represented by the slope of the green line in Fig. $4 c$, the accumulated contribution difference grows little for weak convergence and then rapidly for moderate strengths, while the growth slows down again for strong to extreme strengths. We have confirmed that, even if we choose divergence maxima near $36^{\circ} \mathrm{N}$ as a target box in place of the northern $\left(\sim 40^{\circ} \mathrm{N}\right)$ maxima (see Fig. 1a), the moderate events makes 2.4 times as large a contribution as strong to extreme events to the meridional contrast.

In Fig. 4a, the two standard deviations of the surface convergence is $4.68 \times 10^{-5} \mathrm{~s}^{-1}\left(5.16 \times 10^{-5} \mathrm{~s}^{-1}\right)$ for the red (blue) histogram. The contribution to the mean frontalscale meridional contrast from convergence/divergence whose amplitude is larger than the two standard deviations is as small as $0.09 \times 10^{-5} \mathrm{~s}^{-1}\left(0.04 \times 10^{-5} \mathrm{~s}^{-1}\right)$ according to the green lines in Fig. 4c, which is negligible compared with that from moderate events (Table 2). These results further confirm that the "extreme" events defined by O'Neill et al. (2017) play only a secondary role in shaping the frontalscale time-mean surface wind convergence/divergence contrast across the KE Front.

\section{b. Horizontal distributions of frequency and contribution}

In the following, horizontal distributions of frequency and contributions from local convergence or divergence events with particular strength are investigated. Figure 5 shows horizontal distributions of locally evaluated frequencies (Figs. 5a-f) of different categories of surface wind convergence/divergence and their corresponding contributions to the local climatological-mean values (Figs. 5g-1). For example, for Fig. 5e, the number of time steps that exhibit convergence with magnitude larger than $1.2 \times 10^{-5} \mathrm{~s}^{-1}$ and smaller than $4.0 \times 10^{-5} \mathrm{~s}^{-1}$ is counted for each grid $\left[N_{\operatorname{bin}(i)}(x, y)\right.$, where $x$ and $y$ signify longitude and latitude, respectively] and then divided by $3472\left(N_{\text {all }}=28\right.$ years $\times 31$ days $\times 4$ time steps a day $)$. Here, $N_{\text {all }}$ has the same value for any of the locations and panels, while $N_{\text {bin }(i)}(x, y)$ varies spatially. For each of the contribution distributions, the area-averaged value has been subtracted locally to highlight their horizontal inhomogeneity. Thus, the simple summation of Figs. $5 \mathrm{~g}-1$ yields the same horizontal structure as in the climatologicalmean field, while the spatial average, which is exactly zero by definition, slightly deviates from the climatologicalmean counterpart. The horizontal distribution of the frequency of surface wind convergence events in moderate strength exhibits distinct peaks along the KE axis (Fig. 5e), where the climatological convergence also maximizes. The corresponding contribution (Fig. 5k) yields distinct horizontal inhomogeneity, featuring a zonal band of local maxima of convergence along the $\mathrm{KE}$ and a southwest-northeast-oriented band of local minima along the Oyashio Front, both of which coincide well with their climatological-mean counterpart. By contrast, strong to extreme convergence events yield much higher horizontal homogeneity (Fig. 51). Although a zonally elongated band of weaker convergence maxima is hinted along the $\mathrm{KE}$, it

TABLE 2. Contributions from weak, moderate, and strong to extreme events of surface wind convergence $\left(10^{-5} \mathrm{~s}^{-1}\right)$, corresponding to the individual lines in Fig. 4c. Each of the contributions is evaluated as the difference between accumulated contribution values at the larger and smaller threshold of each category. The rightmost column indicates the ratio of the contribution from moderate events to that from strong to extreme events.

\begin{tabular}{lllll}
\hline \hline & & & & \multicolumn{2}{c}{ Ratio (moderate/strong } \\
& \multicolumn{1}{c}{$0-1.21$ (weak) } & $1.21-4.01$ (moderate) & $>4.01$ (strong to extreme) & to extreme) \\
\hline Red line (warm side) & $0.14(-0.54$ to -0.40$)$ & $0.59(-0.40$ to 0.19$)$ & $0.48(0.19-0.67)$ & 1.2 \\
Blue line (cool side) & $0.07(-1.26$ to -1.19$)$ & $0.21(-1.19$ to -0.98$)$ & $0.35(-0.98$ to -0.63$)$ & 0.60 \\
Green line (difference) & $0.06(0.73-0.79)$ & $0.39(0.79-1.18)$ & $0.12(1.18-1.30)$ & 3.3 \\
\hline
\end{tabular}




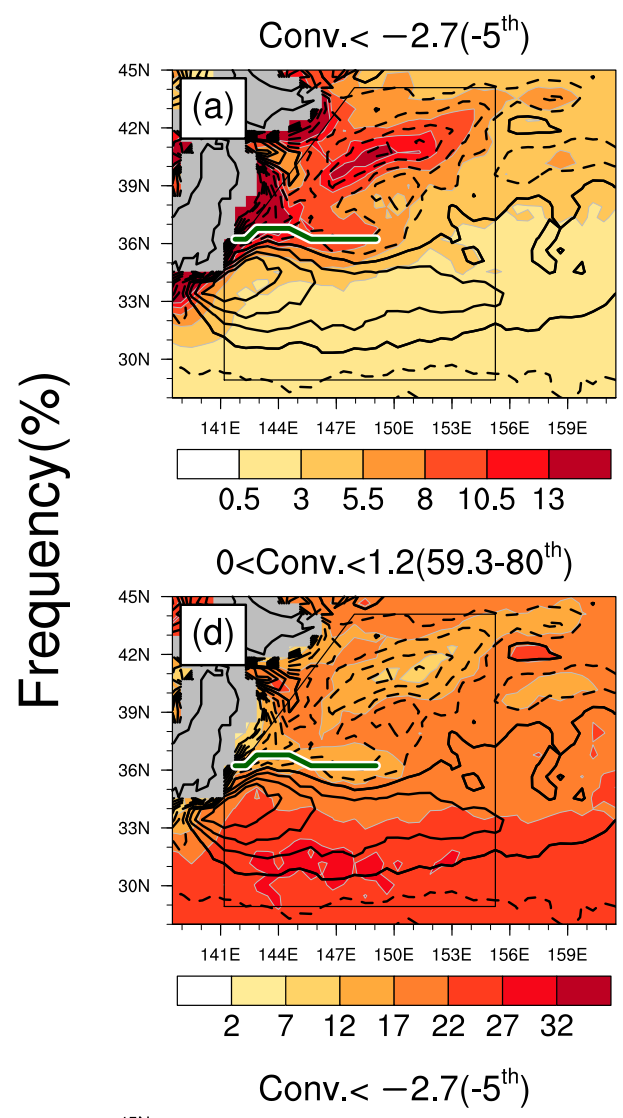

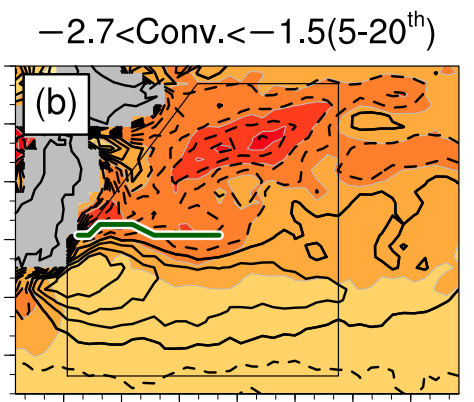

141E $144 \mathrm{E}$ 147E $150 \mathrm{E}$ 153E $156 \mathrm{E}$ 159E

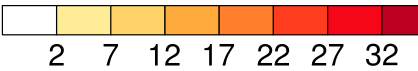

$1.2<$ Conv. $<4.0\left(80-95^{\text {th }}\right)$

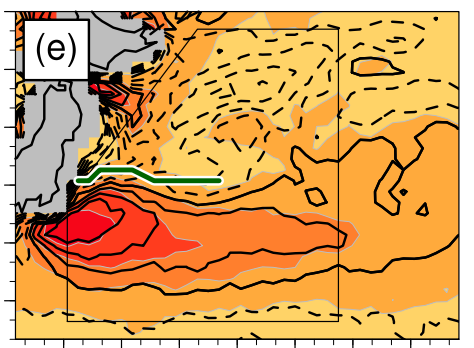

141E 144E $147 \mathrm{E}$ 150E $153 \mathrm{E}$ 156E 159E

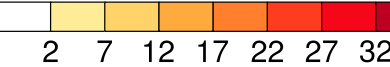

$-2.7<$ Conv. $<-1.5\left(5-20^{\text {th }}\right)$

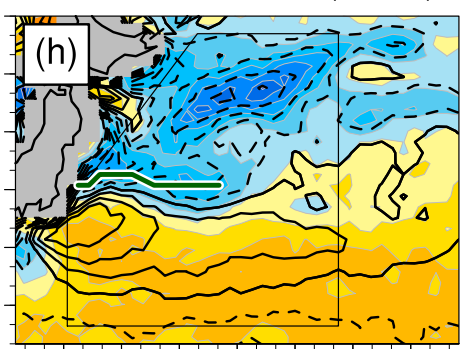

141E 144E 147E 150E 153E 156E 159E

$$
\begin{array}{lllll}
-0.3 & -0.15 & 0 & 0.15 & 0.3
\end{array}
$$

$1.2<$ Conv. $<4.0\left(80-95^{\text {th }}\right)$

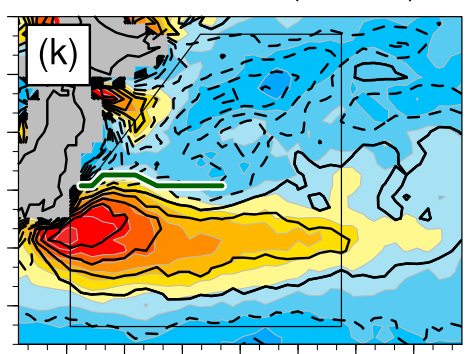

141E 144E 147E 150E 153E 156E 159E

$\begin{array}{lllll}-0.3 & -0.15 & 0 & 0.15 & 0.3\end{array}$
$-1.5<$ Conv. $<0\left(20-59.3^{\text {th }}\right)$

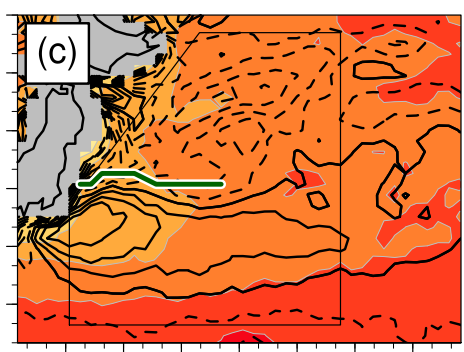

141E 144E 147E $150 \mathrm{E}$ 153E $156 \mathrm{E}$ 159E

$\begin{array}{lllllll}4 & 14 & 24 & 34 & 44 & 54 & 64\end{array}$ $4.0<$ Conv. $\left(95^{\text {th }}-\right)$

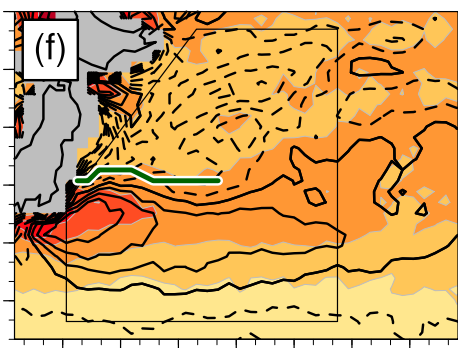

141E $144 \mathrm{E}$ 147E $150 \mathrm{E}$ 153E 156E $159 \mathrm{E}$

$\begin{array}{llllll}0.5 & 3 & 5.5 & 8 & 10.5 & 13\end{array}$

$-1.5<$ Conv. $<0\left(20-59.3^{\text {th }}\right)$

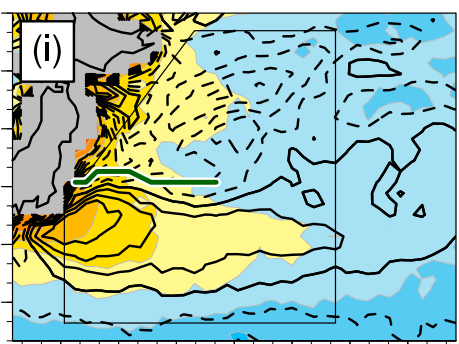

141E 144E 147E 150E 153E 156E 159E

$\begin{array}{lllll}-0.3 & -0.15 & 0 & 0.15 & 0.3\end{array}$

$4.0<$ Conv. $\left(95^{\text {th }}-\right)$

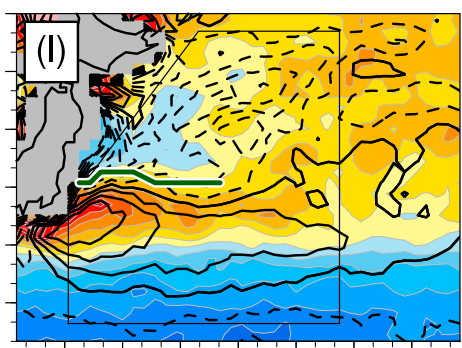

141E 144E 147E 150E 153E 156E 159E

$\begin{array}{lllll}-0.3 & -0.15 & 0 & 0.15 & 0.3\end{array}$

FIG. 5. (a)-(f) Frequency (\%; shaded as indicated just at the bottom) and (g)-(l) the corresponding contribution $\left(10^{-5} \mathrm{~s}^{-1}\right)$ of 6-hourly surface wind convergence in strengths (negative for divergence) as indicated on the top of each panel, locally evaluated for the period 1985-2012 in January based on JRA-55CHS. Corresponding climatology is superimposed with black contours $\left(10^{-5} \mathrm{~s}^{-1}\right.$; indicated for $\pm 0.1, \pm 0.3, \pm 0.5, \ldots$; negative for divergence). In (g)-(l), the area average within the KOE region as indicated with black lines has been subtracted from each of the contribution fields. Green lines indicate the axis of the KE Front at which climatological-mean horizontal SST gradients are locally maximized. 
TABLE 3. As in Table 2, but for wind divergence events.

\begin{tabular}{lcccc}
\hline \hline & $\begin{array}{c}\text {-2.71 (strong to } \\
\text { extreme) }\end{array}$ & $\begin{array}{c}-2.71 \text { to }-1.54 \\
\text { (moderate) }\end{array}$ & -1.54 to 0 (weak) & $\begin{array}{c}\text { Ratio (moderate/strong } \\
\text { to extreme) }\end{array}$ \\
\hline Red line (warm side) & $-0.10(0.00$ to -0.10$)$ & $-0.22(-0.10$ to -0.32$)$ & $-0.22(-0.32$ to -0.54$)$ & 2.2 \\
Blue line (cool side) & $-0.43(0.00$ to -0.43$)$ & $-0.55(-0.43$ to -0.98$)$ & $-0.28(-0.98$ to -1.26$)$ & 1.3 \\
Green line (difference) & $0.33(0.00-0.33)$ & $0.33(0.33-0.66)$ & $0.07(0.66-0.73)$ & 1.0 \\
\hline
\end{tabular}

is displaced northward relative to the climatological band of convergence maxima. The inhomogeneity of the contribution from weak convergence events is negligible (Fig. 5j).

Likewise, the contribution from moderate divergence events exhibits high horizontal inhomogeneity (Fig. 5h), which reflects well the climatological divergence in the northern portion of the KOE region. The contributions from weak divergence events (Fig. 5i) are found negligible. Unlike those from strong to extreme convergence events (Fig. 51), contributions from strong to extreme divergence events well follow the climatological-mean field near the Oyashio Front (Fig. 5g). Indeed, contribution from the strong to extreme divergence events for the time-mean meridional contrast is comparable to moderate divergence events (third row in Table 3). As discussed in the following section, the vertical mixing effect seems dominant near the Oyashio Front, which can yield strong to extreme divergence under intense cross-frontal equatorward winds (Schneider and Qiu 2015). By contrast, the strong to extreme convergence events, which tend to be larger in amplitude than the strong/extreme divergence events in our classification, are probably associated with developed synoptic-scale cyclones and fronts. This asymmetry is likely a manifestation of the gradient wind balance, which allows greater intensification to cyclones and associated convergence than to anticyclones and associated divergence (e.g., Holton 2004). These results further suggest that both convergence events in moderate amplitudes and divergence events in moderate to extreme amplitudes play a primary role in shaping the frontal-scale timemean patterns in surface wind convergence/divergence around the KOE region.

\section{Typical synoptic situations causing moderate surface wind convergence along the Kuroshio Extension}

In this section, we attempt to identify typical synoptic situations in which surface wind convergence in moderate strength occurs along the KE. First, we chose all events exhibiting surface wind convergence of 1.2-4 $\times$ $10^{-5} \mathrm{~s}^{-1}$ (moderate event) at the center $\left(34^{\circ} \mathrm{N}, 144^{\circ} \mathrm{E}\right)$ of the small rectangular domain near the KE axis. We then classified them into six typical groups by applying cluster analysis for SLP within the KOE domain as indicated with the larger box in Fig. 1a. For the clustering, we utilize the $K$-means clustering method (see appendix B). In this method, the number of clusters has to be specified subjectively, although we have confirmed that essential features are unchanged even if we increase the number of clusters. We have also confirmed that classification through the self-organizing map analysis (Kohonen 2001) yields qualitatively the same results, which therefore suggests that our results are rather insensitive to a particular choice of clustering method.

By examining the temporal evolution of the composited surface convergence and SLP patterns for the individual clusters (Fig. 6), we argue that clusters 1-3 represent typical situations where surface wind convergence is locally enhanced along the KE with a weak SLP trough, which are persistent at least $12 \mathrm{~h}$ (not shown), under the monsoonal northwesterlies behind a developed synoptic-scale cyclone. The surface convergence composited for the three clusters can be regarded as enhancement of the climatological convergence. Meanwhile, clusters 4 and 5 represent the generation of a meso- $\alpha$ cyclone or SLP trough over the KE, where surface convergence is enhanced with statistically significant anomalies despite the weak northwesterlies or even calm conditions over the preceding 12 -h period (not shown). Unlike clusters $1-3$, however, the zonal extent of the convergence is rather limited. Meanwhile, cluster 6 illustrates the passage of a developing synopticscale cyclone, accompanying a broad region of moderate surface convergence. As shown in Fig. 6, clusters 1-5, in which surface wind convergence over the KE is not directly related to passing synoptic-scale cyclones, account for as much as $90 \%$ of the total events of moderate surface wind convergence. These five clusters also exhibit local enhancement in precipitation, which is persistent at least for $12 \mathrm{~h}$ (not shown).

Figure 7 shows longitudinal sections of vertical motion (positive for ascent) right over the $\mathrm{KE}$, composited separately for the six clusters. Clusters $1-3$ feature a zonal band of shallow ascent (Fig. 7, C1-C3). The corresponding meridional sections (Fig. 8, C1-C3) illustrate poleward-tilting ascent over the KE and shallow descent to its north, which represent substantial enhancement of 


\section{Lag:00hr}
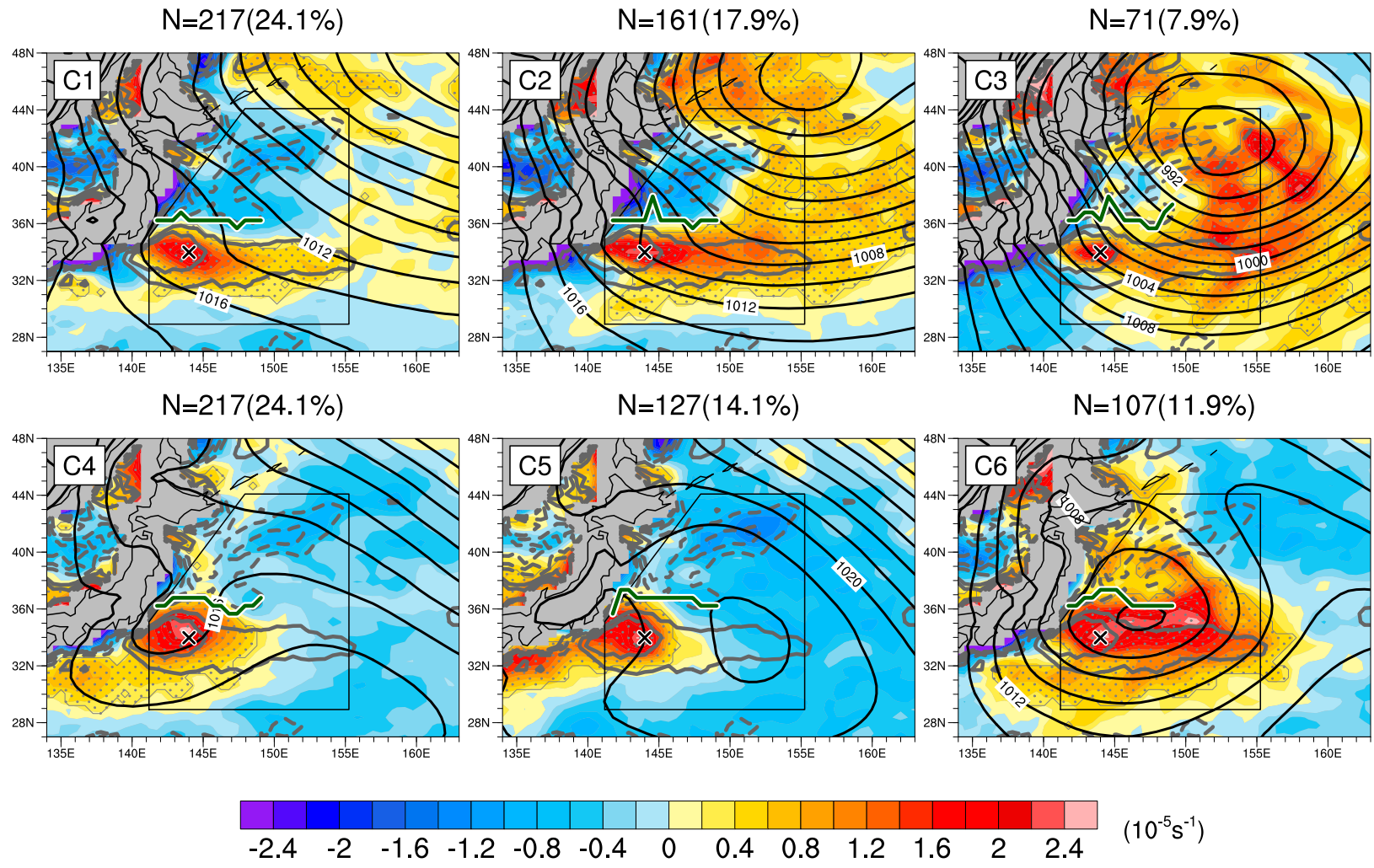

FIG. 6. Composites of surface wind convergence in January (shaded as indicated at the bottom) and SLP (contoured every $2 \mathrm{hPa}$ ) constructed for time steps with surface wind convergence of $1.2-4 \times 10^{-5} \mathrm{~s}^{-1}$ at $33.978^{\circ} \mathrm{N}, 144^{\circ} \mathrm{E}$ (cross mark) based on JRA-55CHS for the period 1985-2012. These events (900 samples in total) are classified into 6 clusters (labeled as C1-C6) by applying the $K$-means clustering method for SLP within the box indicated in each panel. Hatching is applied where the composited surface wind convergence is locally significant at the $98 \%$ confidence level estimated by one-sided bootstrap test with repeating bootstrap sampling 1000 times. Thick gray contours indicate the corresponding climatology of surface wind convergence (every $0.3 \times 10^{-5} \mathrm{~s}^{-1}$; zero contours are omitted). Green lines indicate the axis of the KE Front at which composited-mean horizontal SST gradients are locally maximized.

the corresponding climatological-mean dipolar structure (contoured). Clusters 2 and 3 also indicate deep ascent to the east (Fig. 7, C2-C3), which are probably associated directly with a synoptic-scale cyclone or its accompanying main cold front. Clusters 4 and 5 also exhibit poleward-tilting ascent right over the KE, as a substantial augmentation of its climatological counterpart (Fig. 8, C4-C5). Although its zonal extent is rather limited, the ascent reaches higher altitudes under the near-surface southerlies. In any of the clusters $1-5$, shallow ascent tends to last at least for $12 \mathrm{~h}$ along the $\mathrm{KE}$, while the deep ascent in clusters 3 and 6 moves away eastward faster (not shown).

Our cluster and composite analyses suggest that the clusters represent essential elements for shaping enhanced time-mean surface wind convergence, ascent, and precipitation along the KE. Specifically, they illustrate locally persistent surface wind convergence under the northwesterlies (C1-C3) and generation of a meso- $\alpha$ cyclone or
SLP trough (C4 and C5). In the next section, we show specific events that typify those clusters.

\section{Case study for the KOE region}

\section{a. Latitude-time sections}

In this section, we investigate selected events that typify the composited structures in the individual clusters. For this purpose, we have selected January in 1987 and 2012. As shown in Fig. 9a, monthly mean surface wind convergence in January 1987 exhibits a zonally coherent structure along the $\mathrm{KE}$ as in its climatology, as their spatial cross correlation is the highest (0.86) among the 28 years. Therefore, this January can illustrate a typical wintertime daily evolution. January 2012 is characterized by the enhanced SST gradients along the KE (Fig. 9d). Besides, there were only two distinct synoptic-scale disturbances as discussed below, while there were five or more 
Lag:00hr (Lat.=32.85-35.10)
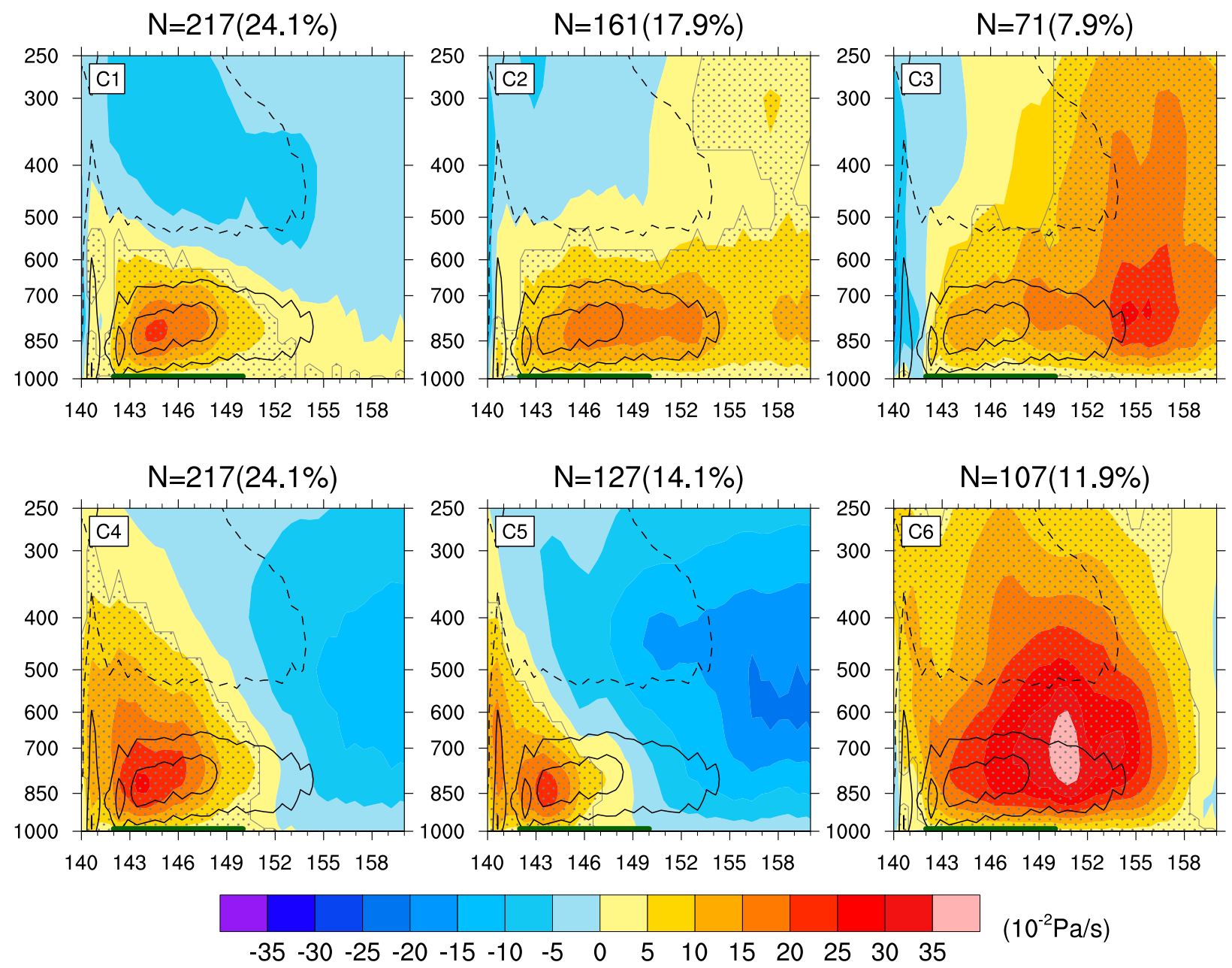

$\left(10^{-2} \mathrm{~Pa} / \mathrm{s}\right)$

FIG. 7. As in Fig. 6, but for the corresponding longitudinal sections of vertical velocity as sign-reversed pressure velocity (shaded) and its climatology (contoured every $3 \times 10^{-2} \mathrm{~Pa} \mathrm{~s}^{-1}$; solid lines for upward; zero contours are omitted) meridionally averaged for $32.85^{\circ}-$ $35.10^{\circ} \mathrm{N}$. Thick green lines along the abscissa roughly indicate the climatological zonal extent of the $\mathrm{KE}\left(142^{\circ}-150^{\circ} \mathrm{E}\right)$.

disturbances in other typical Januaries. Thus, distinct impacts of the SST front on relatively calm atmosphere can be expected in January 2012.

Figures $9 \mathrm{~b}$ and $9 \mathrm{e}$ show latitude-time (6-hourly) sections of surface wind convergence averaged zonally across the KOE region. It can be commonly observed between the two Januaries that surface wind convergence (divergence) frequently occurred to the south (north) of the KE Front, marked by the local maximum in monthly mean SST gradients (blue lines in Figs. 9c,f). A close inspection reveals that, after the passage of synoptic-scale cyclones or distinct atmospheric fronts, surface wind convergence tended to persist over the $\mathrm{KE}$ axis. In those sections, the synoptic events are manifested as narrow stripes of convergence extending into the north of the KE Front, as typically seen on 4, 8,
17, 24, and 30 January 1987, and 3 and 24 January 2012 (black arrows). Any of the persistent convergence events around the KE immediately after those synoptic events is classified into one of the clusters $1-3$, and they tended to be accompanied by distinct surface northerlies (indicated by solid contours). Although passages of synoptic-scale disturbances were less frequent in 2012 than in 1987, surface wind convergence was still frequently observed over the KE axis, for example, on 6 , 10 , and 19 January, which did not necessarily accompany the northerlies with speed greater than $3 \mathrm{~m} \mathrm{~s}^{-1}$ and are mostly classified into cluster 4 or 5 .

\section{b. Time evolution and persistent atmospheric fronts}

Among the several events of pronounced convergence events around the KE listed above, the two specific 


\section{Lag:00hr (Lon.=144.00-146.81)}
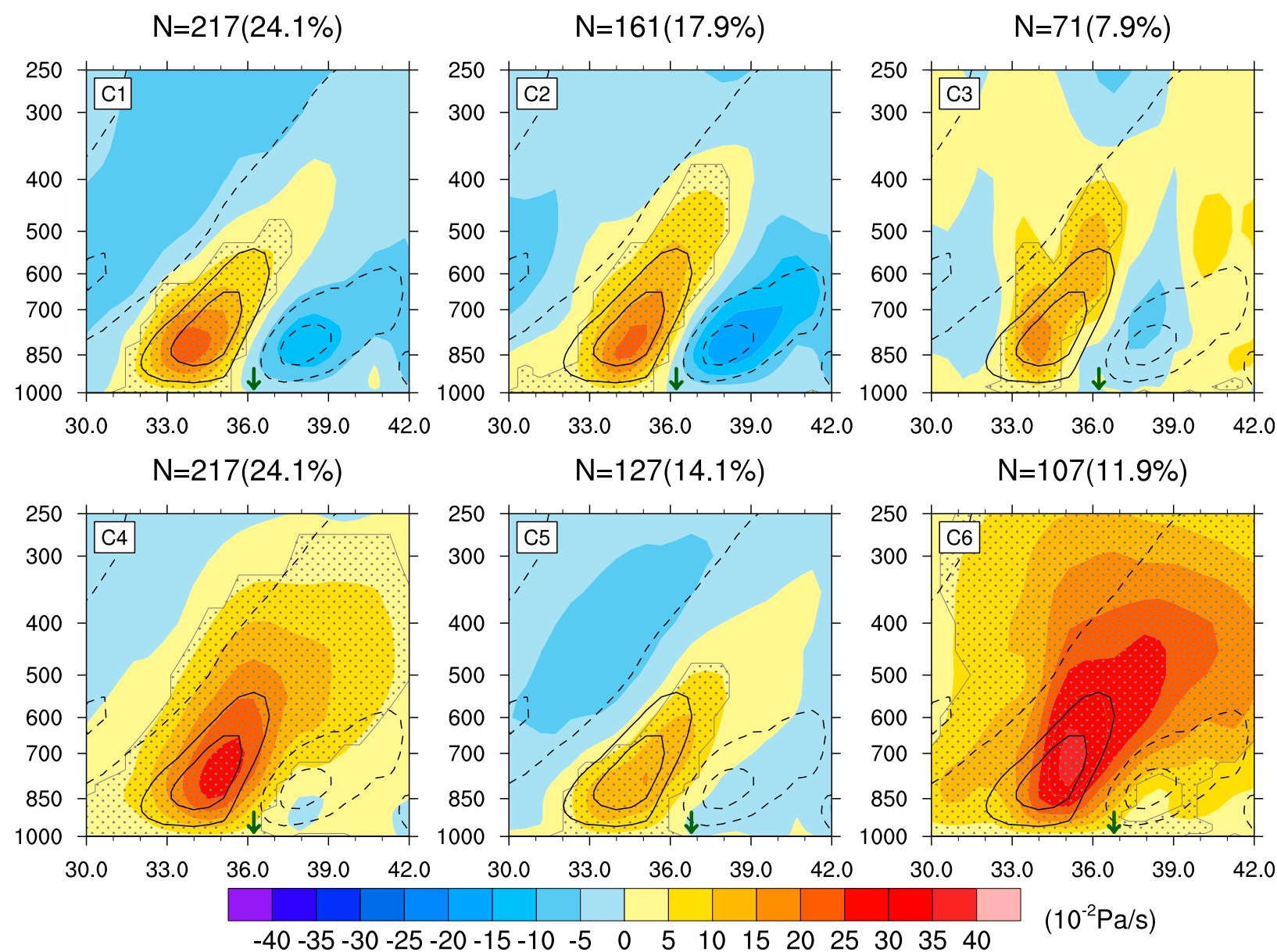

FIG. 8. As in Fig. 7, but for the corresponding meridional section after averaged for $144^{\circ}-146.81^{\circ}$ E. Green arrows indicate latitudinal position of the KE Front at which composited equatorward SST gradients are maximized.

events are investigated in detail; one is 0600 UTC 9 January-0600 UTC 10 January 1987 and the other 0600 UTC 6 January-0600 UTC 7 January 2012. Specifically, the former event started as cluster 1 (0000 UTC 9 January) and evolved into cluster 2 (0600 UTC 9 January-0600 UTC 10 January). The latter event also started as cluster 1 (0600 UTC 6 January), then evolved into cluster 4 (1800 UTC 6 January and 0000 UTC 7 January) and finally into cluster 1 (0600 UTC 7 January).

\section{1) 0600 UTC 9 JANUARY-0600 10 JANUARY 1987}

Upper panels in Fig. 10 show 6-hourly evolution of surface wind convergence (shaded) and SLP (contoured) for 0600 UTC 9 January-0600 UTC 10 January 1987. Near-surface atmospheric fronts detected with a thermal frontal parameter (appendix C) are superimposed with thick black lines. A synoptic-scale cyclone was migrating eastward far north of the KE. At 1200 UTC
9 January, a zonally elongated band of surface wind convergence in moderate strength formed along the KE behind a meridionally oriented cold front, which is the main frontal system of the cyclone accompanying extreme surface wind convergence. Although the main cold front passed the KE region quickly by 1200 UTC 9 January, a zonal band of wind convergence persisted along the KE at least another $18 \mathrm{~h}$ until 0600 UTC 10 January. The convergence zone was accompanied by a zonally oriented stationary atmospheric front that remained behind the main cyclone and was anchored along the KE. As in the cluster 2 composites, the convergence zone accompanied ascent at the 925- (not shown) and 600-hPa levels (middle panels in Fig. 10) as well as a precipitation band (lower panels in Fig. 10). The precipitation band is shifted slightly to the north of the convergence zone consistently with the northward tilting of ascent (Fig. 8). Although precipitation in reanalyses can be sensitive to the forecast models, 

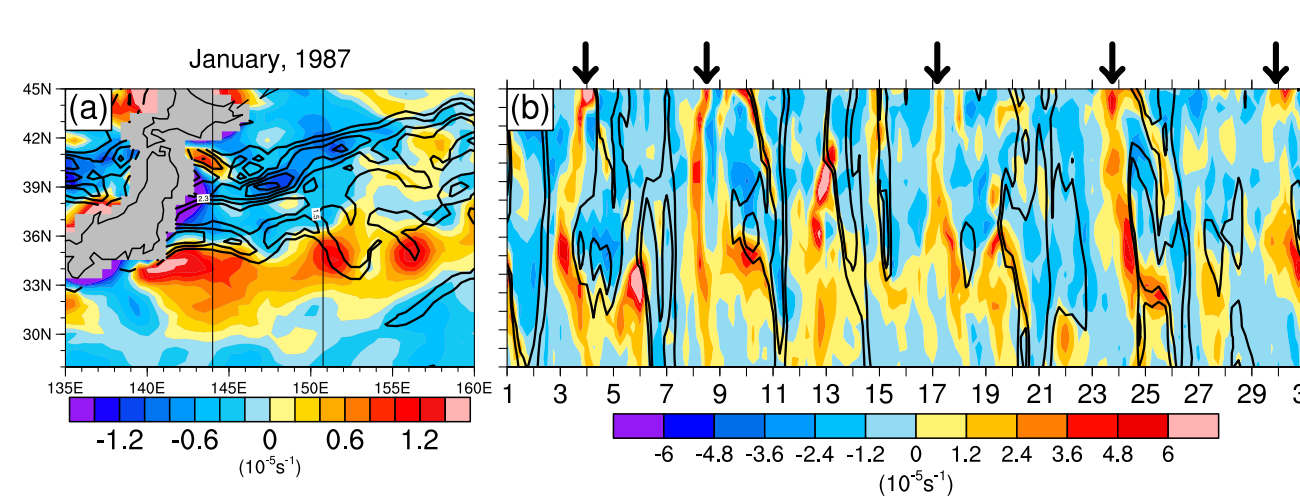

$\left({ }^{\circ} \mathrm{C} / 100 \mathrm{~km}\right)$
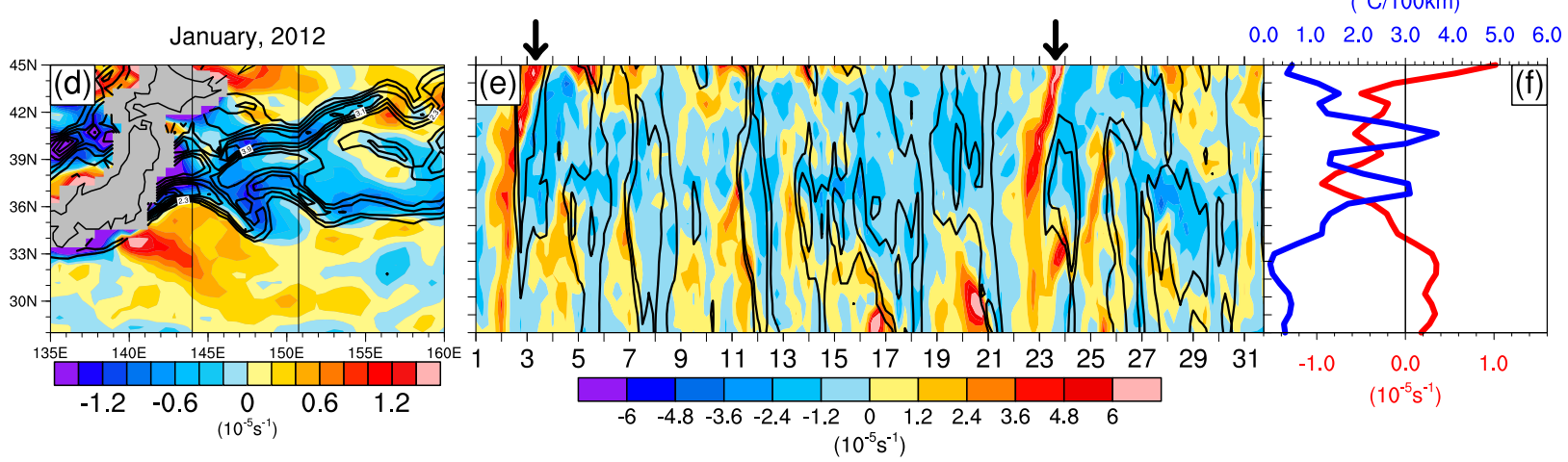

FIG. 9. (a) Monthly mean fields of surface wind convergence (shaded as indicated at the bottom) and equatorward SST gradients [contoured for every $1.5^{\circ} \mathrm{C}(100 \mathrm{~km})^{-1}$ from $0.8^{\circ} \mathrm{C}(100 \mathrm{~km})^{-1}$ ] over the KOE region in January 1987. (b) Latitude (ordinate)-time (abscissa; 6-hourly; labels indicate calendar days) sections of surface wind convergence (shaded as indicated just to the bottom) and meridional wind at $10 \mathrm{~m}$ (contoured only for -6 and $-9 \mathrm{~m} \mathrm{~s}^{-1}$ with solid lines) averaged over $144^{\circ}-150.75^{\circ} \mathrm{E}$ as indicated in (a), and (c) the corresponding monthly mean latitudinal profiles of surface wind convergence $\left(10^{-5} \mathrm{~s}^{-1}\right.$; red lines; bottom red axis) and SST gradients $\left[{ }^{\circ} \mathrm{C}(100 \mathrm{~km})^{-1}\right.$; blue lines; top blue axis] zonally averaged for the same longitudinal sector. (d)-(f) As in (a)-(c), respectively, but for January 2012.

we have verified that ERA5 exhibits consistent distributions for this event and the two other events shown below (see the online supplemental material).

\section{2) 0600 UTC 6 JANUARY-0600 UTC 7 JANUARY 2012}

In the case of 0600 UTC 6 January-0600 UTC 7 January 2012 (Fig. 11), a meso- $\alpha$ cyclone was generated over the $\mathrm{KE}$ under the weak background northwesterlies associated with a well-developed synoptic-scale cyclone to its far northeast. The eastward-moving meso- $\alpha$ cyclone then developed into a synoptic-scale system, accompanying precipitation and ascent in the lower and midtroposphere. The distinct amplification of the meso- $\alpha$ cyclone shares some common features with cluster 6 as well.

A similar SLP trough is frequently observed along the $\mathrm{KE}$ under the monsoonal northwesterlies even if there is no distinct synoptic-scale cyclone to its northeast, as typified by the situation at 1800 UTC 9 January 2010 (Fig. 12). This situation is reminiscent of the climatologicalmean SLP trough shown by Tanimoto et al. (2011). Indeed, cluster 1 seems to include those events with generation of weak SLP troughs under the northwesterlies and stationary atmospheric fronts.

The generation of a meso- $\alpha$ cyclone or SLP trough may be through the hydrostatic effect over the warm KE and additional feedback processes discussed later. Furthermore, the Honshu Island is known to topographically induce surface wind convergence near the KE off the Boso Peninsula under the northwesterlies (e.g., Kawase et al. 2006). A detailed assessment of their relative roles is left for a future work.

\section{c. Stationary atmospheric fronts along the $K E$}

Figure 10 suggests the particular importance of stationary atmospheric fronts in shaping time-mean maxima in surface wind convergence, ascent aloft and precipitation along the KE. In fact, detection frequency of atmospheric fronts on a 6-hourly basis is maximized locally along the KE Front for any of the six clusters we have identified (Fig. 13). Particularly in clusters 1-3, the detection frequently remains high along the KE Front 

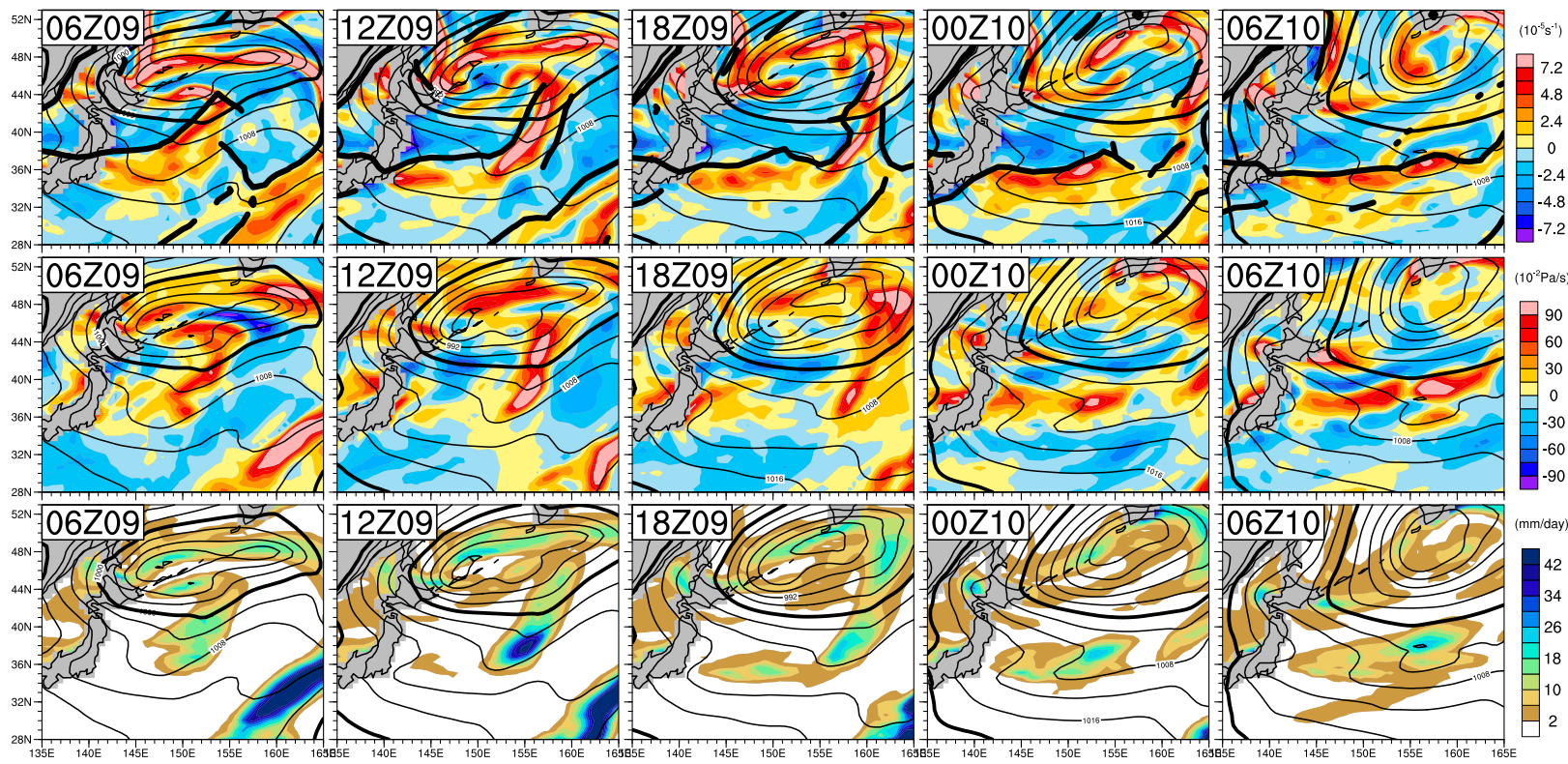

FIG. 10. Snapshots of 6-hourly SLP (contoured for every $4 \mathrm{hPa}$; thickened for 1000 and $1020 \mathrm{hPa}$ ) superimposed on (top) surface wind convergence (shaded as indicated to the right), (middle) vertical velocity as sign-reversed pressure vertical velocity at $600 \mathrm{hPa}$ (shaded), and (bottom) total precipitation (shaded) for the 24-h period from 0600 UTC 9 Jan 1987. Thick lines in the top panels indicate an atmospheric front at the $925-\mathrm{hPa}$ level detected objectively with a thermal frontal parameter.

over the following $12 \mathrm{~h}$ behind the developed synopticscale cyclones (not shown). Note that the detection frequency is particularly high off the southern coast of Japan along the Kuroshio, which probably reflects pronounced land-sea thermal contrast in winter.
The climatological detection frequency of atmospheric fronts is locally enhanced along the sharp SST fronts associated with the KE (Fig. 14a), in agreement with the corresponding DJF climatology obtained by recent studies through a different detection method
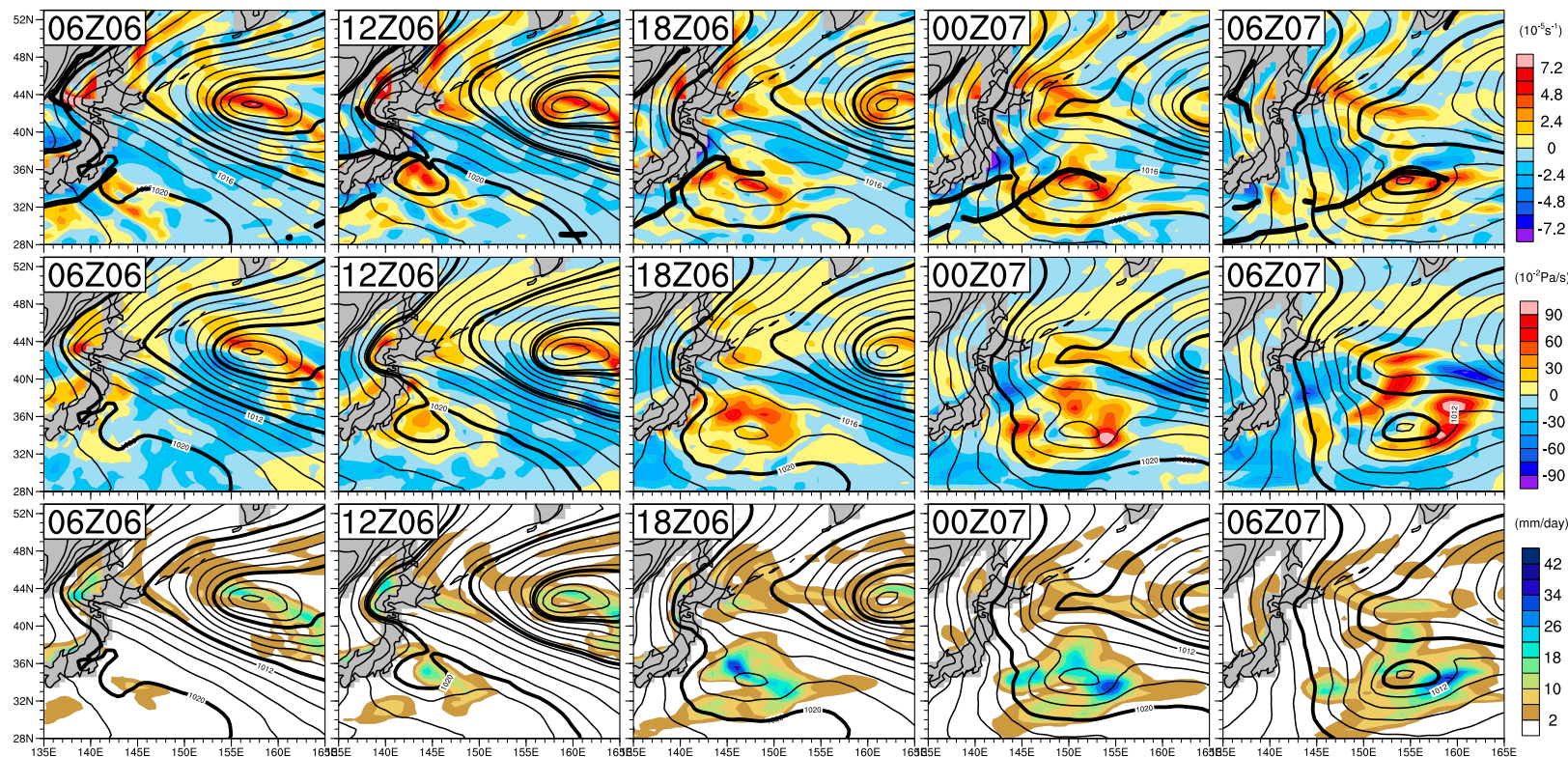

FIG. 11. As in Fig. 10, but for the 24-h period from 0600 UTC 6 Jan 2012. Contour intervals for SLP are 2 hPa (thickened for 990, 1000, 1010 , and $1020 \mathrm{hPa})$ 

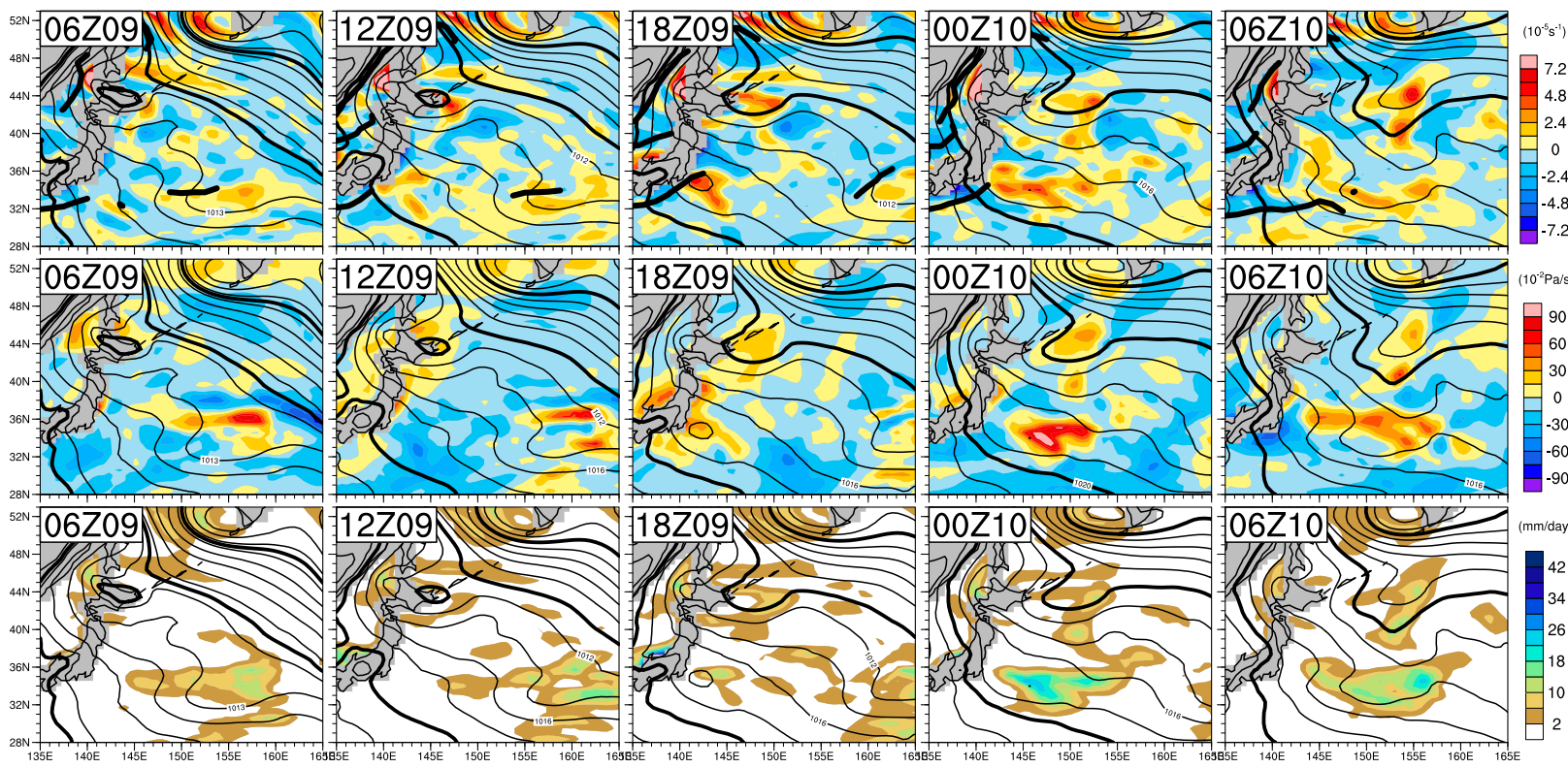

FIG. 12. As in Fig. 10, but for the 24-h period from 0600 UTC 9 Jan 2010.

(Parfitt et al. 2017a). Figure 14b shows persistence of the detected fronts, which is measured as a period in which a given atmospheric front is detected successively at a particular location and locally averaged across all the frontal events. The persistence thus obtained tends to be particularly high around the SST fronts along the KE, where the corresponding persistence of surface wind convergence also tends to maximize (not shown). These results strongly suggest that stationary atmospheric fronts anchored along the SST fronts can play an important role in shaping time-mean surface wind convergence maxima along the $\mathrm{KE}$ axis.

\section{Specific mechanisms}

In this section, we offer a comprehensive argument on the specific processes operative in shaping the persistent surface wind convergence and ascent along the KE. We have confirmed that clusters 1-3 exhibit qualitatively similar features under the northwesterly background winds. We thus show cluster 2 composites only (Fig. 15), which exhibits the strongest wind convergence among the three (Fig. 6). Likewise, clusters 4 and 5 show overall similar structures under calm conditions, and we thus focus on cluster 4 (Fig. 16).

Figure 15 shows horizontal distributions of several variables composited for cluster 2. Upward surface turbulent heat fluxes are augmented around the KE Fronts under the surface northwesterlies behind a developed synoptic cyclone (Fig. 15b). To the north of the KE Front, surface winds are overall divergent (Fig. 15a), owing probably to the vertical mixing effect acting on the strong surface northwesterlies blowing across the prominent Oyashio Front from its colder to warmer side (Spall 2007; Kilpatrick et al. 2014; Schneider and Qiu 2015). Contrastingly, the winds are more parallel to the KE Front, and therefore the vertical mixing effect is less effective. Rather, the MABL locally warms along the KE axis (Fig. 15f), to lower SLP locally (Fig. 15e) and thus yield surface wind convergence (Fig. 15a). This result suggests the importance of the hydrostatic effect.

Furthermore, the surface wind convergence accompanies local enhancement in ascent, convective precipitation (Fig. 15c), and associated latent heating in the upper MABL (Fig. 15d), which can in turn reinforce the convective ascent up to higher elevations. At the same time, the latent heat release can further warm the MABL, acting to deepen the SLP trough and thereby leading to enhanced surface wind convergence. Since the KE is much warmer than the Oyashio, moisture can play a more important role. These composited fields therefore suggest that the localized surface wind convergence along the $\mathrm{KE}$ is initiated by the hydrostatic effect, then reinforced and maintained by positive feedback processes mediated by convective heating. Furthermore, sharp contrast in diabatic heating across the KE Front can act to anchor atmospheric fronts, as discussed by Parfitt et al. (2016). We leave it for our future work to perform more detailed diagnosis with the frontogenetical function (e.g., Hoskins 1982; Masunaga et al. 2015). Note that convective precipitation peaks to the east of KE probably associated with major 


\section{Lag:00hr}
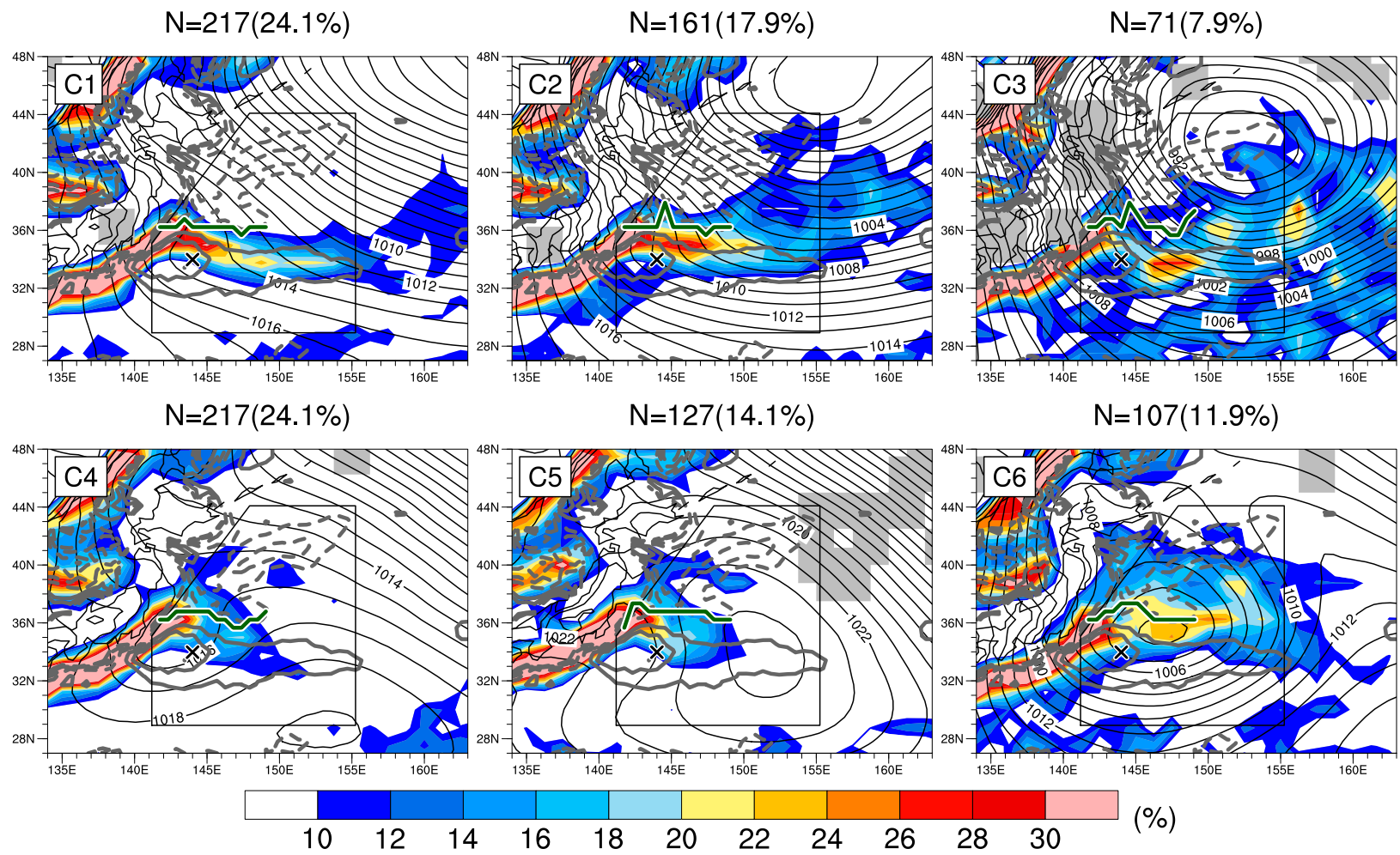

FIG. 13. As in Fig. 6, but the corresponding local detection frequency of atmospheric fronts at 925-hPa level (\%; shaded) in place of surface wind convergence composites.

atmospheric fronts, which can be seen in the case study (e.g., 1200 UTC 9 January in Fig. 10).

Despite rather weak surface winds, cluster 4 still exhibits local enhancement of upward turbulent heat fluxes and diabatic heating along the KE (Fig. 16). The strong surface wind convergence is attributable to enhanced convective precipitation over the KE. In fact, the ascent reaches higher altitudes in the composites for clusters 4 and 5 than in those for clusters 1-3 (Figs. 7 and 8). We therefore conclude that, although their relative importance varies under different synoptic environments, the processes described above are operative in inducing moderate but persistent surface wind convergence confined meridionally along the $\mathrm{KE}$, contributing primarily to the time-mean local surface wind convergence maxima and the distinct contrast with the divergence to the north of $\mathrm{KE}$.

\section{Summary and discussion}

In the present study, the processes and mechanisms for shaping the climatological frontal-scale atmospheric (a) $\mathrm{KOE}$, Frequency, January, $925 \mathrm{hPa}$

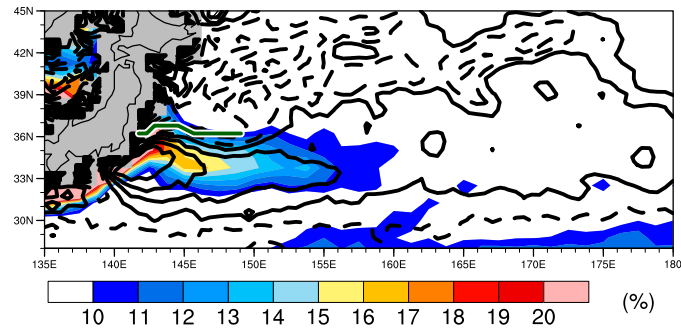

(b) KOE, Duration, January, $925 \mathrm{hPa}$

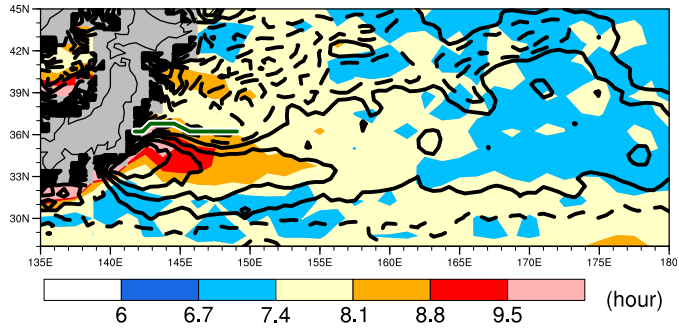

FIG. 14. (a) Local detection frequency (\%; shaded) and (b) duration (hours; shaded) of atmospheric fronts at the 925-hPa level in January over the KOE region for 1985-2012. Green lines indicate the position of KE fronts at which climatological-mean horizontal SST gradients are locally maximized. 
Conv.

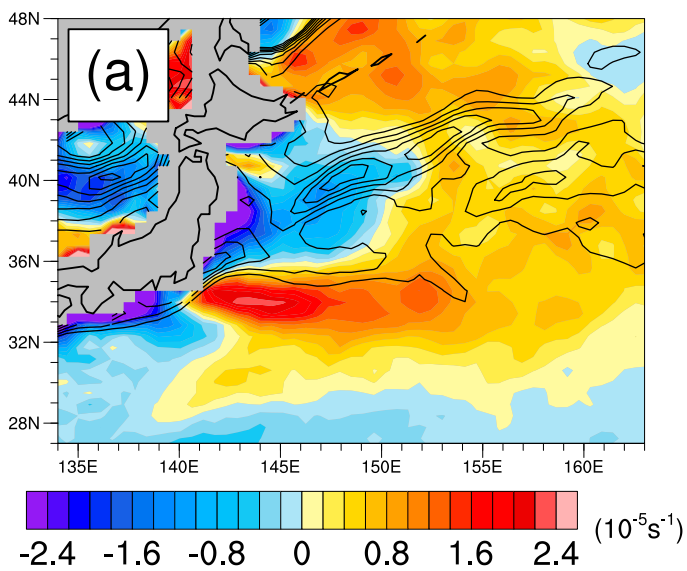

Convective precip.

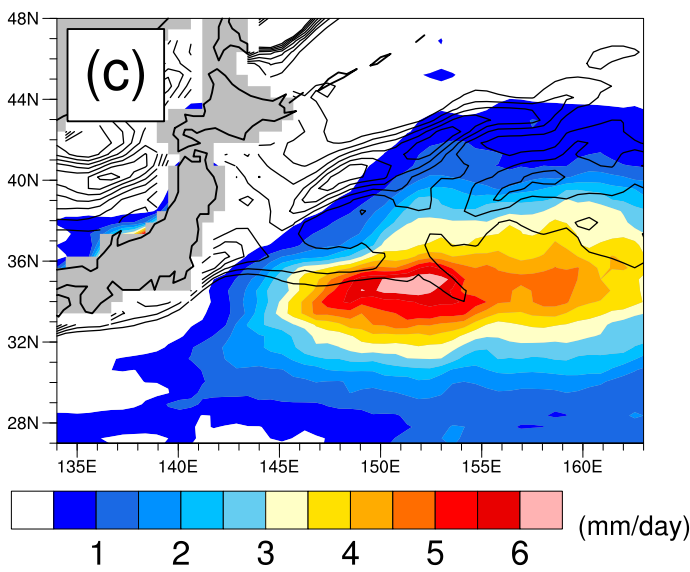

hSLP

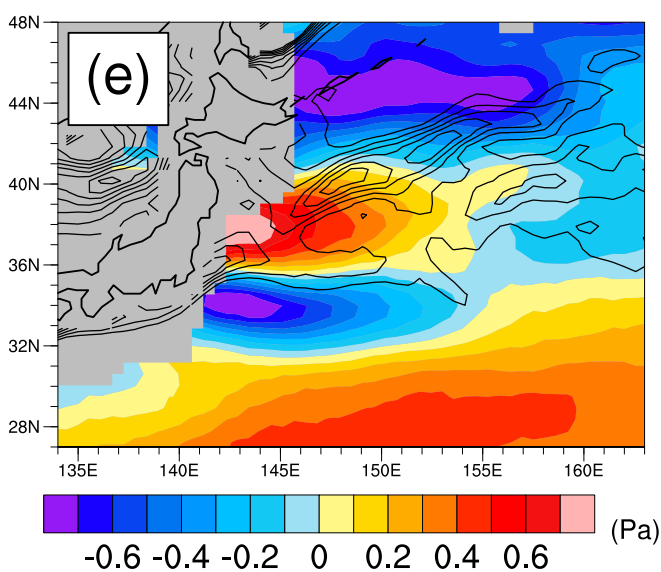

SHF+LHF, wind $10 \mathrm{~m}$
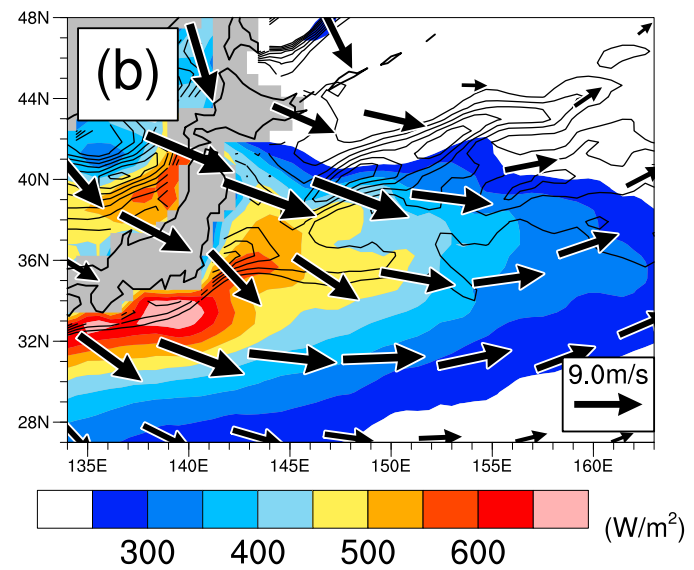

Convective heating

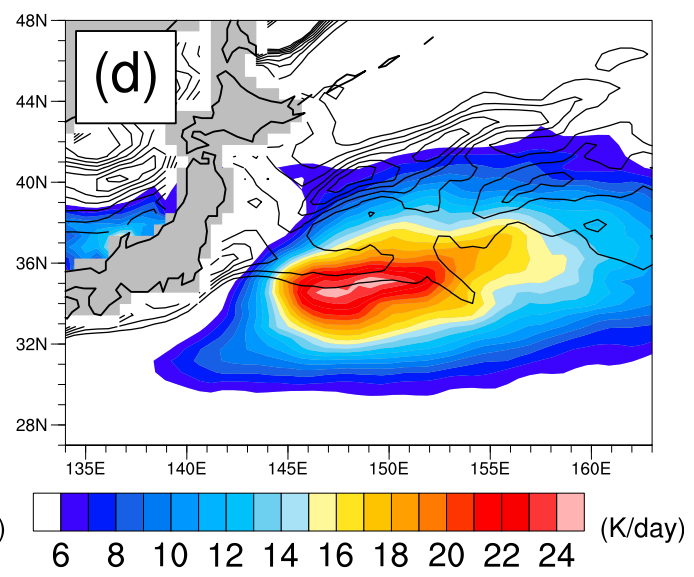

hT(Psfc-850hPa)

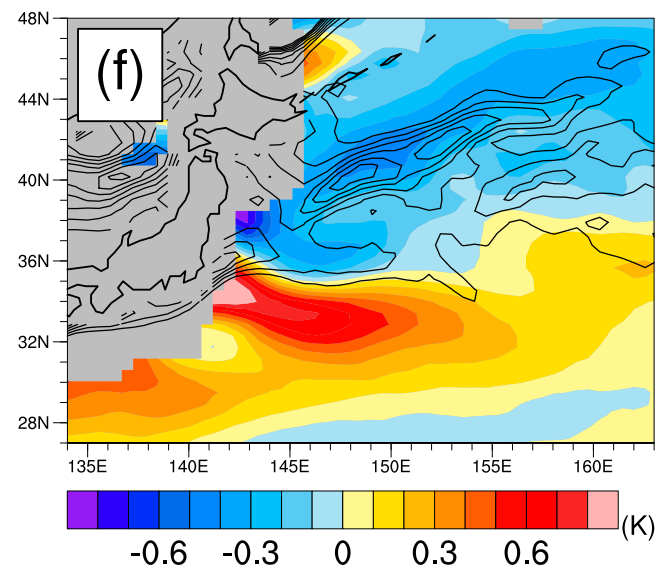

FIG. 15. (a) Surface wind convergence composited for cluster 2 for the KOE region as shown in Fig. 6 (shaded as indicated at the bottom), (b) upward surface turbulent sensible and latent heat fluxes combined (shaded) and surface wind vectors (reference vector at the bottom-right of the panel), (c) convective precipitation (shaded), (d) convective heating at the $850-\mathrm{hPa}$ level (shaded), (e) meridionally high-pass-filtered SLP (shaded), and (f) meridionally high-pass-filtered temperature averaged from the surface to the 850 -hPa level. The meridional high-pass filter is defined as local deviations from $\sim 7^{\circ}$ latitudinal running means. Contours indicate the corresponding composites of SST gradients [every $0.5^{\circ} \mathrm{C}(100 \mathrm{~km})^{-1}$ from $0.1^{\circ} \mathrm{C}(100 \mathrm{~km})^{-1}$ ]. 
Conv.

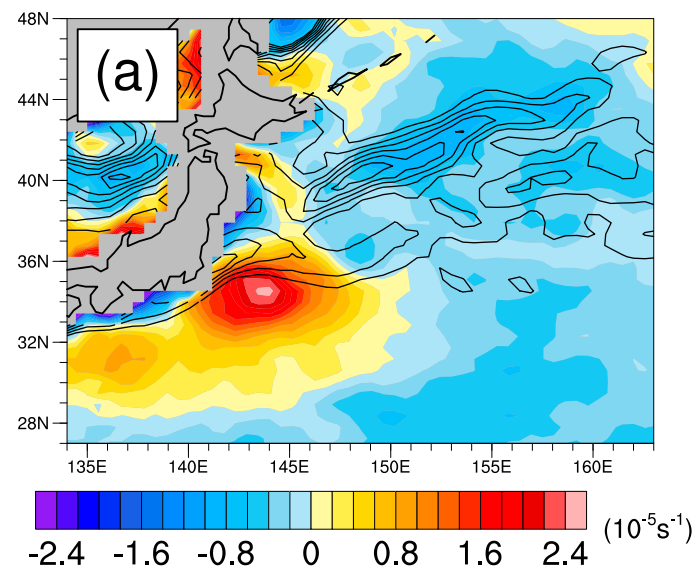

Convective precip.

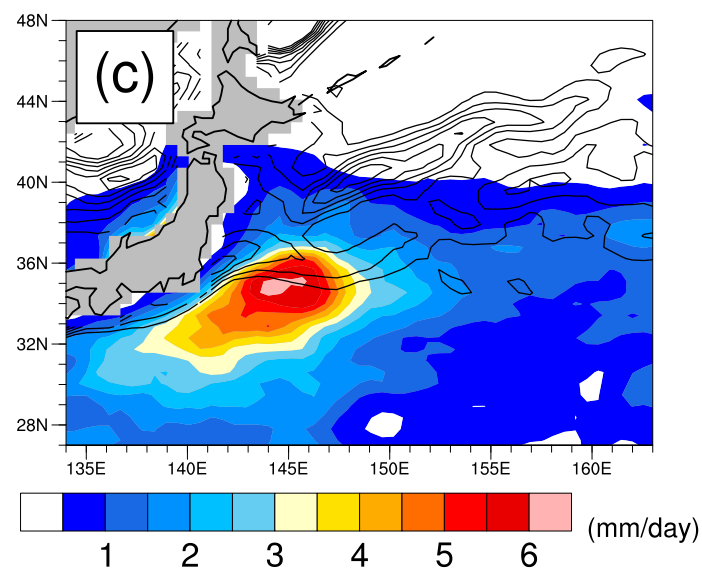

hSLP

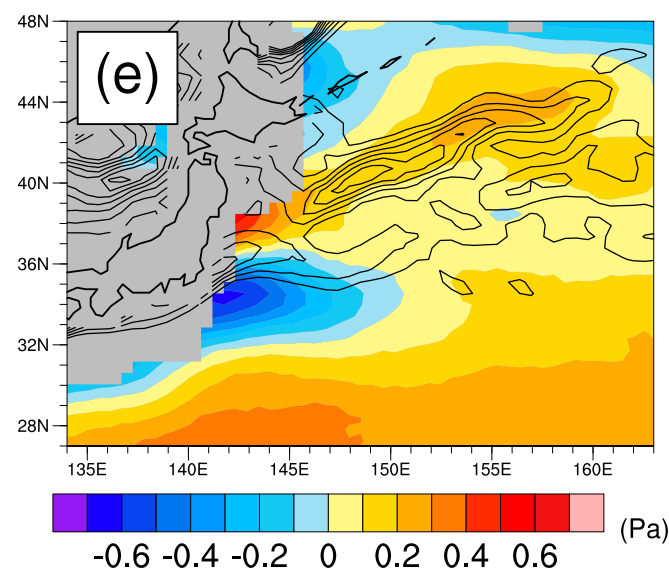

$\mathrm{SHF}+\mathrm{LHF}$, wind $10 \mathrm{~m}$
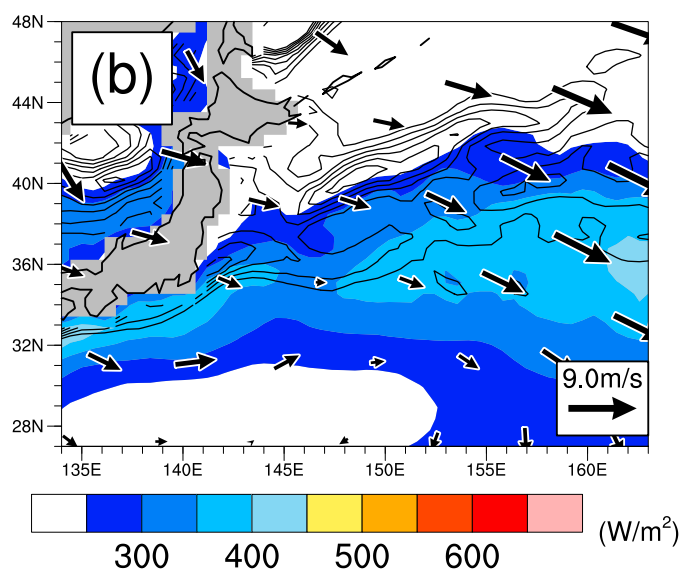

Convective heating

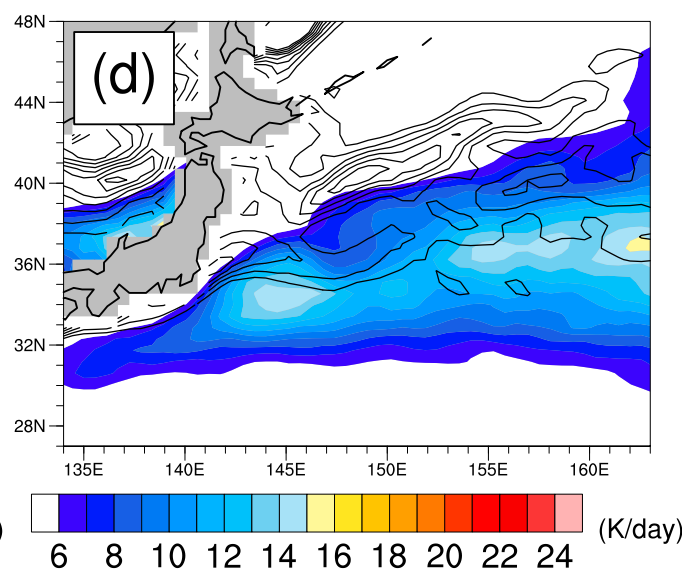

hT(Psfc-850hPa)

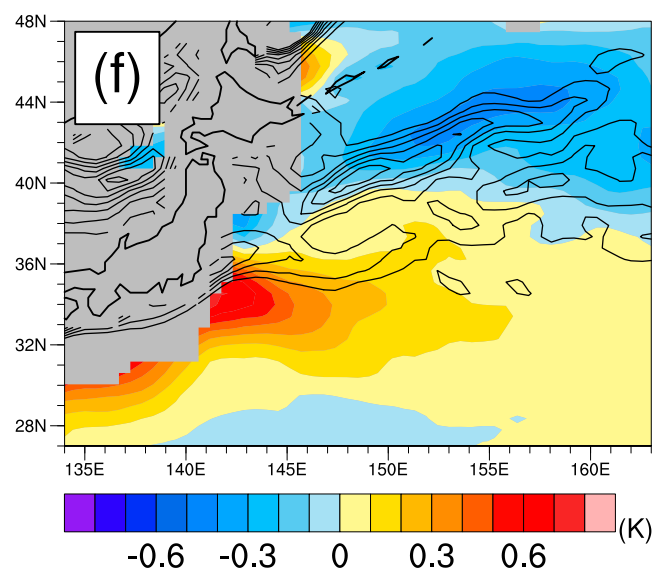

FIG. 16. As in Fig. 15, but for cluster 4. 
patterns around the KE have been explored. As discussed in the previous studies (e.g., O'Neill et al. 2017; Parfitt and Czaja 2016), atmospheric disturbances leave significant imprints on the time-mean fields and we have therefore examined wind convergence events on daily scales.

By examining frequency and corresponding contributions to the climatological-mean distribution, daily scale surface wind convergence in moderate strength and divergence in moderate-to-extreme strength are found to play a primary role in shaping time-mean frontal-scale inhomogeneity characterized by convergence maxima over the warm $\mathrm{KE}$ axis and divergence maxima poleward. Strong to extreme convergence events are confirmed to climatologically yield surface convergence in a spatially homogeneous manner, as also pointed out by O'Neill et al. (2017)

Our cluster analysis and case studies have revealed that stationary atmospheric fronts or generation of a meso- $\alpha$ cyclone or SLP trough plays an essential role in shaping the time-mean convergence peak along the KE. These processes are likely to induce moderate but persistent surface wind convergence localized along the KE axis, unlike in the vicinity of a developed synoptic-scale cyclone and associated primary atmospheric fronts. Nevertheless, the moderate surface convergence tends to accompany ascent in the lower and midtroposphere and precipitation, manifested as augmentation of their climatological-mean structures. These events are more frequent and persistent than migratory synoptic-scale system, while more occasional than expected from local MABL processes, where continuous imprints of SST fronts are assumed. Therefore, these events are difficult to identify in simple time-mean statistics, consistent with Parfitt and Czaja (2016) and O'Neill et al. (2017).

In the present study, specific processes have been explored by examining composited structures based on cluster analysis. The typical structures are likely to emerge under the monsoonal northwesterlies, which augment surface turbulent heat fluxes over the $\mathrm{KE}$ and thus warm the MABL locally. This hydrostatic effect leads to the formation of a SLP trough, surface wind convergence, and associated shallow ascent. The associated convective precipitation and latent heating in the upper MABL can reinforce the ascent reaching into the free troposphere, which in turn act to deepen the SLP trough further and thereby reinforce the surface wind convergence. Meanwhile, the vertical mixing effect is effective in the northern portion of the KOE region, where monsoonal surface northwesterlies tend to cross the prominent Oyashio Front from its colder to warmer side to yield surface wind divergence. The surface wind convergence is thus localized and enhanced along the KE axis, which leads to the marked climatological-mean surface wind convergence/ divergence contrast. Furthermore, we argue that the localized convective heating as well as pronounced contrasts in heat supply from the ocean across the KE Front can anchor atmospheric fronts, leading to frequent and persistent atmospheric fronts along the KE. Thus, evaluating the moist processes can be an important step forward toward our deeper understanding of frontal-scale atmospheric features, in addition to dry processes (Kilpatrick et al. 2014, 2016; Schneider and Qiu 2015).

To the formation of the time-mean surface wind divergence maxima to the poleward of the KE, surface wind divergence events in both moderate and strong to extreme strength contribute significantly. Their occurrences are more frequent right over the oceanic SST fronts (Fig. 5). To the poleward of the KE axis, surface winds tend to remain divergent (Fig. 9), interrupted occasionally by strong to extreme convergence events associated with synoptic-scale storms. Our close inspection has revealed further that surface divergence tends to be augmented under the equatorward winds crossing the SST front from its colder to warmer sides, which is consistent with previous studies (Wallace et al. 1989; Hayes et al. 1989; Spall 2007; Kilpatrick et al. 2014; Schneider and Qiu 2015). We thus consider that the vertical mixing effect acting on the equatorward surface winds associated with monsoonal circulation and/or passage of synoptic-scale disturbances is effective in yielding the time-mean surface wind divergence maxima near the Oyashio Front. The mechanism is most effective for surface winds crossing the fronts perpendicularly from their cooler side. Meanwhile, surface winds are more parallel to the SST fronts near the KE (Fig. 6), in which the hydrostatic effect should be more effective.

The present study has thus addressed the specific processes and mechanisms in shaping the frontal-scale timemean patterns in surface wind convergence/divergence along the KE. Typical structures in the composites are reminiscent of climatological-mean surface wind and SLP patterns argued by Tokinaga et al. (2009) and Tanimoto et al. (2011). The present study suggests the important role of convective diabatic heating, in addition to the classical hydrostatic effect and vertical mixing effect.

We should emphasize that JRA-55CHS tends to underestimate extreme percentile values compared with satellite observations and our analysis is limited to midwinter, which can lead to different interpretations of wind convergence events from O'Neill et al. (2017). Although Parfitt and Seo (2018) also suggested that atmospheric fronts play an important role in shaping the time-mean surface wind convergence field, their strength and persistence are not particularly argued. Given that their method identifies atmospheric fronts much more frequently ( $\sim 25 \%)$ than the TFP method ( 16\%; Fig. $14 \mathrm{a})$, their 
"frontal average" is likely to include additional contributions from weak and stationary atmospheric fronts with moderate surface wind convergence, which are featured in the present study. Furthermore, since their front detection method uses wind vorticity as well as temperature gradients, the meso- $\alpha$ cyclones discussed in the present study (Fig. 6, C4 and C5) can also be included in their frontal average. Our results thus do not contradict Parfitt and Seo (2018), but we present more detailed and comprehensive perspective through cluster analysis and case studies.

While this paper focuses on the KOE region, we have confirmed that the Gulf Stream region in the northwestern Atlantic, the Agulhas Current region in south Indian Ocean, and Brazil/Malvinas Current region in the South Atlantic overall exhibit qualitatively similar statistical features. We will examine the details in our future work. Since the present study is based on atmospheric reanalysis products, we will also verify our results with satellite observations in our future work. Furthermore, we will compare JRA-55CHS and JRA55C (Kobayashi et al. 2014), the latter for which $1^{\circ}$ resolution SST data are prescribed (Masunaga et al. 2018), to explicitly assess the role of SST fronts.

Acknowledgments. This work is based on RM's doctoral dissertation at the University of Tokyo. Valuable comments by Professors M. Watanabe, Y. N. Takayabu. T. Tozuka, H. Miura, and Y. Kosaka are acknowledged. We also thank Drs. H. Kamahori, C. Kobayashi, and Y. Ota for their continuous effort to produce JRA-55CHS. We also thank Professor Larry O'Neill and two anonymous reviewers for their sound criticism and constructive comments that helped improve the manuscript. This study is supported in part by the Japanese Ministry of Education, Culture, Sports, Science and Technology (MEXT) through Grants-in-Aid for Scientific Research 16H01844 and through the Arctic Challenge for Sustainability (ArCS) Program, and by the Japan Science and Technology Agency through Belmont Forum CRA "InterDec." RM is partly supported by Grant-in-Aid for JSPS Research Fellow. This study contains modified Copernicus Climate Change Service information (2019). QuikSCAT data are produced by Remote Sensing Systems and sponsored by the NASA Ocean Vector Winds Science Team. Data are available at www.remss.com.

\section{APPENDIX A}

\section{Contribution from "Extreme Events" Based on QuikSCAT data}

In this appendix, the statistical analysis shown in section 3 is repeated using QuikSCAT. Since the data
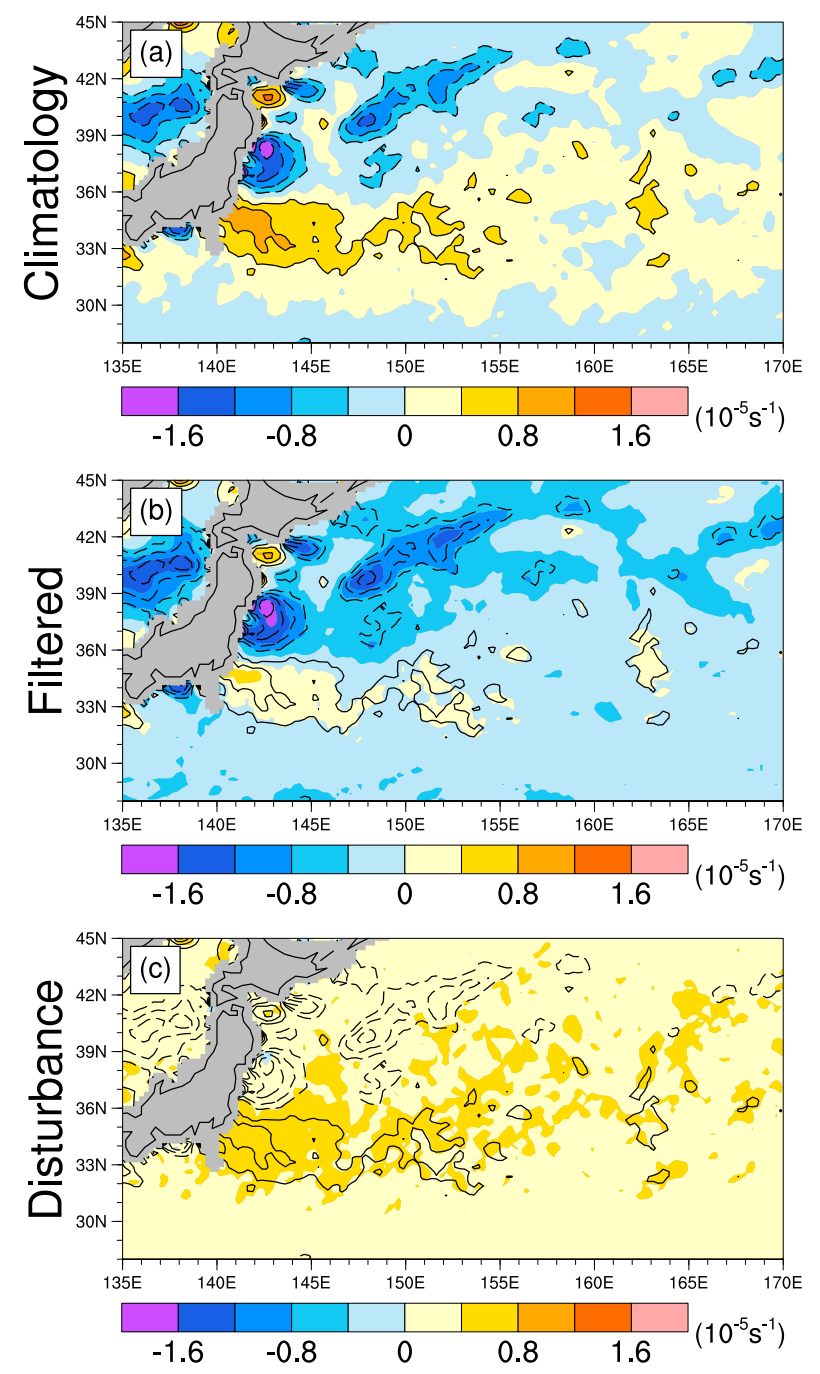

FIG. A1. As in Fig. 3, but based on QuikSCAT for DJF for the period 2000-09. Contours indicate the corresponding seasonal climatologies (every $0.4 \times 10^{-5} \mathrm{~s}^{-1}$ ).

period is limited to 10 years, we constructed the same statistics for three winter months (DJF) rather than only for January as in section 3 . We have confirmed that the corresponding DJF statistics based on the JRA-55CHS (not shown) are similar to their January counterpart (Figs. 1-3). We omit skewness fields, which are quite noisy and exhibit no organized structure.

The disturbance component of QuikSCAT (Fig. A1) evaluated as the difference between the 10-yr climatology and extreme-value-filtered distribution exhibits a higher level of inhomogeneity than its JRA-55CHS counterpart, with more pronounced enhancement of surface convergence along the KE. Nevertheless, this component ubiquitously yields convergence, and it is therefore unlikely to play the primary role in shaping the distinct meridional convergence/divergence contrast in 


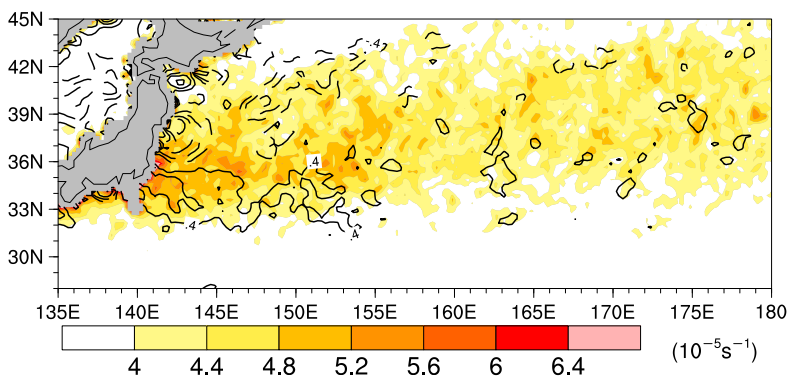

FIG. A2. Horizontal distributions of standard deviation (shaded; $10^{-5} \mathrm{~s}^{-1}$ ) of DJF surface wind convergence over the KuroshioOyashio Extension region for the period 2000-09 based on QuikSCAT. Contours indicate the corresponding seasonal climatology (every $0.4 \times 10^{-5} \mathrm{~s}^{-1}$ ).

the climatological-mean field. Indeed, the standard deviation of surface convergence tends to maximize slightly poleward of time-mean surface wind convergence maxima (Fig. A2) in a manner consistent with its JRA-55CHS counterpart (Fig. 1).

\section{APPENDIX B}

\section{$K$-Means Clustering Method}

In this appendix, we describe the algorithm of the $K$-means clustering method used in our analysis. First, the number of clusters $K$ into which input samples are classified is specified. Samples with sample size $N$ of an arbitrary variable (e.g., SLP) with $M$ spatial points, which are expressed with $M$-dimensional vectors $\mathbf{X}_{i}(i=1, \ldots, N)$, are randomly classified into $K$ clusters as an initial classification. The centroid of a given cluster $\mathbf{C}_{k}$ is evaluated as

$$
\mathbf{C}_{k}=\frac{1}{N_{k}} \sum_{\mathbf{x} \in Q_{k}} \mathbf{X}_{i}
$$

where $k=1, \ldots, K$. In (B1), $Q_{k}$ signifies a group into which a particular $\mathbf{X}_{i}$ is classified, and the corresponding number of samples is indicated as $N_{k}$. The Euclidean distance between $\mathbf{X}_{i}$ and $\mathbf{C}_{k}$ given as

$$
\left|\mathbf{C}_{k}-\mathbf{X}_{i}\right|,
$$

where $k=1, \ldots, K$, is estimated for each $i$, and then $\mathbf{X}_{i}$ are reassigned into the particular cluster $k$ that yields the smallest Euclidian distance. If one of $\mathbf{X}_{i}$ changes its cluster after all the $\mathbf{X}_{i}$ has been examined, $\mathbf{C}_{k}$ has to be updated according to the new classification. The same procedure as above is repeated until no $\mathbf{X}_{i}$ changes the classification in the reassignment process.

\section{APPENDIX C}

\section{Thermal Frontal Parameter}

The thermal frontal parameter (TFP) is one of the most widely used measures to objectively detect atmospheric fronts from gridded data. According to Hewson (1998), the TFP is defined as

$$
\mathrm{TFP} \equiv-\nabla|\nabla \tau| \cdot \frac{\nabla \tau}{|\nabla \tau|}
$$

Here, $\tau$ is any suitable thermodynamic variable, such as potential temperature. TFP expresses "the gradient of the magnitude of the gradient of a thermodynamic scalar quantity, resolved into the direction of the gradient of the quantity" (Renard and Clarke 1965). Simply, TFP corresponds to maximized second-order spatial derivative. Following Schemm et al. (2015), we use equivalent potential temperature $\theta_{e}$ as $\tau$, estimated through approximate equations proposed by Bolton (1980). We regard lines of TFP $=0$ with $\left|\nabla \theta_{e} \geq 3 \mathrm{~K}(100 \mathrm{~km})^{-1}\right|$ at $925 \mathrm{hPa}$ as near-surface atmospheric fronts. For detecting atmospheric fronts, we use the JRA-55CHS data rearranged on $1.25^{\circ}$ grid intervals, rather than on the original $0.56^{\circ}$ grid intervals, to avoid noisy and suspicious results.

We can obtain positions of a given atmospheric front on every lattice that the front crosses. We then identify the nearest grid point to the detected frontal position as a "frontal grid" to construct related statistics, including frequency and persistence, of the detected fronts. Note that, in the weather chart provided by the JMA, a front is identified as the equatorward edge of the corresponding frontal zone where gradients in thermodynamic variables are pronounced, and thus atmospheric fronts detected in the present study are shifted systematically poleward from those detected by JMA's definition. Furthermore, it should be kept in mind that JMA's weather charts illustrate primary atmospheric fronts only for brevity, by omitting most of the weak and/or secondary atmospheric fronts.

\section{REFERENCES}

Bolton, D., 1980: The computation of equivalent potential temperature. Mon. Wea. Rev., 108, 1046-1053, https://doi.org/ 10.1175/1520-0493(1980)108<1046:TCOEPT > 2.0.CO;2.

Chelton, D. B., and S. P. Xie, 2010: Coupled ocean-atmosphere interaction at oceanic mesoscales. Oceanography, 23, 52-69, https://doi.org/10.5670/oceanog.2010.05.

Copernicus Climate Change Service, 2017: ERA5: Fifth generation of ECMWF atmospheric reanalysis of the global climate. Copernicus Climate Change Service Climate Data Store, accessed 23 April 2019, https://cds.climate.copernicus.eu/ cdsapp\#!/home. 
Harada, Y., and Coauthors, 2016: The JRA-55 Reanalysis: Representation of atmospheric circulation and climate variability. J. Meteor. Soc. Japan, 94, 269-302, https://doi.org/10.2151/jmsj.2016-015.

Hayes, S. P., M. J. McPhaden, and J. M. Wallace, 1989: The Influence of sea-surface temperature on surface wind in the eastern equatorial Pacific: Weekly to monthly variability. J. Climate, 2, 1500-1506, https://doi.org/10.1175/ 1520-0442(1989)002<1500:TIOSST > 2.0.CO;2.

Hersbach, H., and Coauthors, 2018: Operational global reanalysis: Progress, future directions and synergies with NWP. ERA Report Series 27, 63 pp., https://www.ecmwf.int/node/18765.

Hewson, T. D., 1998: Objective fronts. Meteor. Appl., 5, 37-65, https://doi.org/10.1017/S1350482798000553.

Holton, J. R., 2004: An Introduction to Dynamic Meteorology. 4th ed. Academic Press, 535 pp.

Hoskins, B. J., 1982: The mathematical theory of frontogenesis. Annu. Rev. Fluid Mech., 14, 131-151, https://doi.org/10.1146/ annurev.fl.14.010182.001023.

— J. Atmos. Sci., 47, 1854-1864, https://doi.org/10.1175/15200469(1990)047<1854:OTEOST > 2.0.CO;2.

Hotta, D., and H. Nakamura, 2011: On the significance of the sensible heat supply from the ocean in the maintenance of the mean baroclinicity along storm tracks. J. Climate, 24, 33773401, https://doi.org/10.1175/2010JCLI3910.1.

Ishii, M., A. Shouji, S. Sugimoto, and T. Masumoto, 2005: Objective analysis of sea-surface temperature and marine meteorological variables for the 20th century using ICOADS and the KOBE Collection. Int. J. Climatol., 25, 865-879, https:// doi.org/10.1002/joc.1169.

Kawase, H., Y. Takeuchi, T. Sato, and F. Kimura, 2006: Precipitable water vapor around orographically induced convergence line. SOLA, 2, 25-28, https://doi.org/10.2151/sola.2006-007.

Kilpatrick, T., N. Schneider, and B. Qiu, 2014: Boundary layer convergence induced by strong winds across a midlatitude SST front. J. Climate, 27, 1698-1718, https://doi.org/10.1175/JCLID-13-00101.1.

,-- , and — 2016: Atmospheric response to a midlatitude SST front: Along-front winds. J. Atmos. Sci., 73, 3489-3509, https://doi.org/10.1175/JAS-D-15-0312.1.

Kobayashi, C., H. Endo, Y. Ota, S. Kobayashi, H. Onoda, Y. Harada, K. Onogi, and H. Kamahori, 2014: Preliminary results of the JRA-55C, an atmospheric reanalysis assimilating conventional observations only. SOLA, 10, 78-82, https:// doi.org/10.2151/sola.2014-016.

Kobayashi, S., and Coauthors, 2015: The JRA-55 Reanalysis: General specifications and basic characteristics. J. Meteor. Soc. Japan, 93, 5-48, https://doi.org/10.2151/jmsj.2015-001.

Kohonen, T., 2001: Self-Organizing Maps. 3rd ed. Springer, $501 \mathrm{pp}$

Kwon, Y.-O., M. A. Alexander, N. A. Bond, C. Frankignoul, H. Nakamura, B. Qiu, and L. A. Thompson, 2010: Role of the Gulf Stream and Kuroshio-Oyashio systems in large-scale atmosphere-ocean interaction: A review. J. Climate, 23, 32493281, https://doi.org/10.1175/2010JCLI3343.1.

Lindzen, R. S., and S. Nigam, 1987: On the role of sea surface temperature gradients in forcing low-level winds and convergence in the tropics. J. Atmos. Sci., 44, 2418-2436, https://doi.org/10.1175/ 1520-0469(1987)044<2418:OTROSS >2.0.CO;2.

Masunaga, R., H. Nakamura, T. Miyasaka, K. Nishii, and Y. Tanimoto, 2015: Separation of climatological imprints of the Kuroshio Extension and Oyashio fronts on the wintertime atmospheric boundary layer: Their sensitivity to SST resolution prescribed for atmospheric reanalysis. J. Climate, 28, 1764-1787, https://doi.org/10.1175/JCLI-D-14-00314.1.

,,,$--- \ldots$, and B. Qiu, 2016: Interannual modulations of oceanic imprints on the wintertime atmospheric boundary layer under the changing dynamical regimes of the Kuroshio Extension. J. Climate, 29, 3273-3296, https://doi.org/10.1175/ JCLI-D-15-0545.1.

, H. Kamahori, K. Onogi, and S. Okajima, 2018: JRA55CHS: An atmospheric reanalysis produced with highresolution SST. Sci. Online Lett. Atmos., 14, https://doi.org/ 10.2151/sola.2018-002.

Minobe, S., A. Kuwano-Yoshida, N. Komori, S. P. Xie, and R. J. Small, 2008: Influence of the Gulf Stream on the troposphere. Nature, 452, 206-209, https://doi.org/10.1038/nature06690.

—-, M. Miyashita, A. Kuwano-Yoshida, H. Tokinaga, and S. P. Xie, 2010: Atmospheric response to the Gulf Stream: Seasonal variations. J. Climate, 23, 3699-3719, https://doi.org/10.1175/2010JCLI3359.1.

Nakamura, H., T. Sampe, Y. Tanimoto, and A. Shimpo, 2004: Observed associations among storm tracks, jet streams and midlatitude oceanic fronts. Earth's Climate: The Ocean-Atmosphere Interaction, Geophys. Monogr., Vol. 147, Amer. Geophys. Union, 329-345, https://doi.org/10.1029/147GM18.

$\longrightarrow,-$, A. Goto, W. Ohfuchi, and S. P. Xie, 2008: On the importance of midlatitude oceanic frontal zones for the mean state and dominant variability in the tropospheric circulation. Geophys. Res. Lett., 35, L15 709, https://doi.org/10.1029/2008GL034010.

O'Neill, L. W., D. B. Chelton, and S. K. Esbensen, 2003: Observations of SST-induced perturbations of the wind stress field over the Southern Ocean on seasonal timescales. J. Climate, 16, 2340-2354, https://doi.org/10.1175/2780.1.

,,$---\longrightarrow$, and F. J. Wentz, 2005: High-resolution satellite measurements of the atmospheric boundary layer response to SST variations along the Agulhas Return Current. J. Climate, 18, 2706-2723, https://doi.org/10.1175/JCLI3415.1.

,$- \ldots$, and $—$ 2010: The effects of SST-induced surface wind speed and direction gradients on midlatitude surface vorticity and divergence. J. Climate, 23, 255-281, https:// doi.org/10.1175/2009JCLI2613.1.

,-- , and — 2012: Covariability of surface wind and stress responses to sea surface temperature fronts. J. Climate, $\mathbf{2 5}$, 5916-5942, https://doi.org/10.1175/JCLI-D-11-00230.1.

_ T. Taack, D. B. Chelton, and E. Skyllingstad, 2017: The Gulf Stream convergence zone in the time-mean winds. J. Atmos. Sci., 74, 2383-2412, https://doi.org/10.1175/JAS-D-16-0213.1.

Ogawa, F., H. Nakamura, K. Nishii, T. Miyasaka, and A. KuwanoYoshida, 2012: Dependence of the climatological axial latitudes of the tropospheric westerlies and storm tracks on the latitude of an extratropical oceanic front. Geophys. Res. Lett., 39, L05804, https://doi.org/10.1029/2011GL049922.

Parfitt, R., and A. Czaja, 2016: On the contribution of synoptic transients to the mean atmospheric state in the Gulf Stream region. Quart. J. Roy. Meteor. Soc., 142, 1554-1561, https://doi.org/ 10.1002/qj.2689.

_ convergence over the Kuroshio Extension and Gulf Stream in wintertime: The role of atmospheric fronts. Geophys. Res. Lett., 45, 9909-9918, https://doi.org/10.1029/2018GL080135.

— A. Czaja, S. Minobe, and A. Kuwano-Yoshida, 2016: The atmospheric frontal response to SST perturbations in the Gulf Stream region. Geophys. Res. Lett., 43, 2299-2306, https:// doi.org/10.1002/2016GL067723.

$\longrightarrow, \ldots$, and Y. O. Kwon, 2017a: The impact of SST resolution change in the ERA-Interim reanalysis on wintertime Gulf 
Stream frontal air-sea interaction. Geophys. Res. Lett., 44, 3246-3254, https://doi.org/10.1002/2017GL073028.

, - _ and H. Seo, 2017b: A simple diagnostic for the detection of atmospheric fronts. Geophys. Res. Lett., 44, 43514358, https://doi.org/10.1002/2017GL073662.

Plougonven, R., A. Foussard, and G. Lapeyre, 2018: Comments on "The Gulf Stream convergence zone in the time-mean winds." J. Atmos. Sci., 75, 2139-2149, https://doi.org/10.1175/JAS-D-17-0369.1.

Renard, R. J., and L. C. Clarke, 1965: Experiments in numerical objective frontal analysis. Mon. Wea. Rev., 93, 547-556, https:// doi.org/10.1175/1520-0493(1965)093<0547:EINOFA > 2.3.CO;2.

Ricciardulli, L., and F. J. Wentz, 2011: Reprocessed QuikSCAT (V04) wind vectors with Ku-2011 geophysical model function. Remote Sensing Systems Rep. 043011, 8 pp., www.remss.com/ missions/qscat.

Sampe, T., H. Nakamura, A. Goto, and W. Ohfuchi, 2010: Significance of a midlatitude SST frontal zone in the formation of a storm track and an eddy-driven westerly jet. J. Climate, 23, 1793-1814, https://doi.org/10.1175/2009JCLI3163.1.

Schemm, S., I. Rudeva, and I. Simmonds, 2015: Extratropical fronts in the lower troposphere-global perspectives obtained from two automated methods. Quart. J. Roy. Meteor. Soc., 141, 1686-1698, https://doi.org/10.1002/qj.2471.

Schneider, N., and B. Qiu, 2015: The atmospheric response to weak sea surface temperature fronts. J. Atmos. Sci., 72, 3356-3377, https://doi.org/10.1175/JAS-D-14-0212.1.

Sheldon, L., A. Czaja, B. Vannière, C. Morcrette, B. Sohet, M. Casado, and D. Smith, 2017: A 'warm path' for Gulf Stream-troposphere interactions. Tellus, 69, 1299397, https:// doi.org/10.1080/16000870.2017.1299397.

Small, R. J., and Coauthors, 2008: Air-sea interaction over ocean fronts and eddies. Dyn. Atmos. Oceans, 45, 274-319, https:// doi.org/10.1016/j.dynatmoce.2008.01.001.

Song, Q., P. Cornillon, and T. Hara, 2006: Surface wind response to oceanic fronts. J. Geophys. Res., 111, C12006, https://doi.org/ 10.1029/2006JC003680.
Spall, M. A., 2007: Midlatitude wind stress-surface temperature coupling in the vicinity of oceanic fronts. J. Climate, 20, 37853801, https://doi.org/10.1175/JCLI4234.1.

Takatama, K., S. Minobe, M. Inatsu, and R. J. Small, 2012: Diagnostics for near- surface wind convergence/divergence response to the Gulf Stream in a regional atmospheric model. Atmos. Sci. Lett., 13, 16-21, https://doi.org/10.1002/asl.355.

$-, \longrightarrow, \ldots$, and ——, 2015: Diagnostics for near-surface wind response to the Gulf Stream in a regional atmospheric model. J. Climate, 28, 238-255, https://doi.org/10.1175/JCLI-D-1300668.1.

Tanimoto, Y., T. Kanenari, H. Tokinaga, and S. P. Xie, 2011: Sea level pressure minimum along the Kuroshio and its extension. J. Climate, 24, 4419-4434, https://doi.org/10.1175/ 2011JCLI4062.1.

Tokinaga, H., Y. Tanimoto, S. P. Xie, T. Sampe, H. Tomita, and H. Ichikawa, 2009: Ocean frontal effects on the vertical development of clouds over the western North Pacific: In situ and satellite observations. J. Climate, 22, 4241-4260, https://doi.org/ 10.1175/2009JCLI2763.1.

Vannière, B., A. Czaja, and H. F. Dacre, 2017: Contribution of the cold sector of extratropical cyclones to mean state features over the Gulf Stream in winter. Quart. J. Roy. Meteor. Soc., 143, 1990-2000, https://doi.org/10.1002/qj.3058.

Wallace, J. M., T. P. Mitchell, and C. Deser, 1989: The influence of sea-surface temperature on surface wind in the eastern equatorial Pacific: Seasonal and interannual variability. J. Climate, 2, 1492-1499, https://doi.org/10.1175/1520-0442(1989)002<1492: TIOSST $>2.0 . \mathrm{CO} ; 2$.

Wang, Y. H., and T. W. Liu, 2015: Observational evidence of frontal-scale atmospheric responses to Kuroshio Extension variability. J. Climate, 28, 9459-9472, https://doi.org/10.1175/ JCLI-D-14-00829.1.

Xie, S. P., 2004: Satellite observations of cool ocean-atmosphere interaction. Bull. Amer. Meteor. Soc., 85, 195-208, https:// doi.org/10.1175/BAMS-85-2-195. 